\title{
Mega Tsunami of the World Oceans: Chevron Dune Formation, Micro-Ejecta, and Rapid Climate Change as the Evidence of Recent Oceanic Bolide Impacts
}

\author{
Viacheslav Gusiakov, Dallas H. Abbott, Edward A. Bryant, W. Bruce Masse, \\ and Dee Breger
}

\begin{abstract}
This paper deals with the physical and environmental effects resulting from oceanic impacts by sizable comets, and the rates and risks associated with such cosmic impacts. Specifically, we investigate two sets of probable oceanic impact events that occurred within the last 5,000 years, one in the Indian Ocean about $2800 \mathrm{BC}$, and the other in the Gulf of Carpentaria (Australia) about AD 536. If validated, they would be the most energetic natural catastrophes occurring during the middle-to-late Holocene with large-scale environmental and historical human effects and consequences. The physical evidence for these two impacts consists of several sets of data: (1) remarkable depositional traces of coastal flooding in dunes (chevron dunes) found in southern Madagascar and along the coast of the Gulf of Carpentaria, (2) the presence of crater candidates (29-km Burckle crater about 1,500 km southeast of Madagascar which dates to within the last 6,000 years and 18-km Kanmare and 12-km Tabban craters with an estimated age of AD $572 \pm 86$ in the southeast corner of the Gulf of Carpentaria), and (3) the presence of quench textured magnetite spherules and nearly pure carbon spherules, teardrop-shaped tektites with trails of ablation, and vitreous material found by cutting-edge laboratory analytical techniques in the upper-most layer of core samples close to the crater candidates.

Although some propose a wind-blown origin for V-shaped chevron dunes that are widely distributed around the coastlines of the Indian Ocean and in the Gulf of Carpentaria, we have evidence in favor of their
\end{abstract}

\footnotetext{
V. Gusiakov $(\square)$

Tsunami Laboratory, ICMMG SD RAS, Novosibirsk 630090, Russia

e-mail: gvk@sscc.ru
}

mega tsunami formation. In southern Madagascar we have documented evidence for tsunami wave run-up reaching $205 \mathrm{~m}$ above sea-level and penetrating up to $45 \mathrm{~km}$ inland along the strike of the chevron axis. Subtly the orientation of the dunes is not aligned to the prevailing wind direction, but to the path of refracted mega-tsunami originating from Burckle impact crater.

The results of our study show that substantive oceanic comet impacts not only have occurred more recently than modeled by astrophysicists, but also that they have profoundly affected Earth's natural systems, climate, and human societies. If validated, they could potentially lead to a major paradigm shift in environmental science by recognizing the role of oceanic impacts in major climate downturns during the middleto-late Holocene that have been well documented already by different techniques (tree-ring anomalies, ice-, lake- and peat bog-cores).

Keywords Oceanic impact · Comets · Tectonic tsunamis

\section{Introduction}

Tsunamis belong to the class of long-period oceanic waves generated by underwater earthquakes, submarine or subaerial landslides or volcanic eruptions. They are among the most dangerous and complex natural phenomena, being responsible for great loss of life and extensive destruction of property in many coastal areas. The tsunami phenomenon includes three overlapping but quite distinct physical stages: the generation of a wave by any external force that disturbs a water column, the propagation of that wave at high 
speed in the open ocean, and finally, the propagation of the tsunami wave through shallow coastal water and the inundation of dry land by run-up. Most tsunamis occur in the Pacific, but they are known in all other areas of the world including the Atlantic and the Indian Oceans, the Mediterranean and many marginal seas. Tsunami-like phenomena can occur even in lakes, large man-made water reservoirs and large rivers.

Destruction from tsunamis results from three main factors: inundation by salt water, impact dynamics, and erosion. Considerable damage is also caused by floating debris that enhances the destructive force of flooding. Flotation and drag forces can destroy frame buildings, overturn railroad cars and move large ships far inland. Ships in harbors and port infrastructure can be damaged by the strong current and surge generated by even a weak tsunami.

An average height for a tsunami, generated by an earthquake with magnitude of 7.5-8.0 (the range where most tsunamigenic earthquakes occur), is between 3 and $10 \mathrm{~m}$ along $100-300 \mathrm{~km}$ of the coastline closest to the epicenter. This height is still within the range of the largest possible storm surges for many coastal locations. However, tsunami have a longer wavelength and can penetrate inland to much greater distances reaching in many places several hundreds of meters and sometimes several kilometers. The current velocity in a tsunami flood can exceed $10 \mathrm{~m} / \mathrm{s}$, being the most important factor in producing great damage and the loss of human lives.

Tsunamis caused by bolide impact undoubtedly share many characteristics in common with those described above, however they also possess a suite of unique features that reflect the size of the impactor, its extraterrestrial composition, the enormous temperatures and pressures that accompany high velocity impact, and the fact that bolide impacts can occur ubiquitously in the world's oceans. Our purpose in this paper is threefold. First, we will set the stage for our discussion of impact generated tsunami events, including climatic implications, by placing these types of events within the context of the historical record of tsunamis caused by seismic, landslide, and volcanic geophysical events. Second, rather than focusing on recent general simulation and modeling exercises that further our understanding of the nature of oceanic impact tsunami propagation and the potential size of resultant coastal run-ups (e.g. Hills and Mader 1997; Gisler et al. 2003), we will draw atten- tion to existing Holocene coastal landforms and sedimentary signatures that appear to be the likely product of tsunamis generated by bolide impacts. Finally, we will focus upon two middle-to-late Holocene oceanic impact events, one that we hypothesize may have occurred in the abyssal Indian Ocean around 4,800 years ago, and the other in the shallow waters of Australia's Gulf of Carpentaria around 1,500 years ago, in order to show the potential of impact generated tsunamis to affect coastlines.

\section{Regular Tectonic Tsunamis - Analysis of Available Historical Data}

The Global Tsunami DataBase (GTDB) Project is a world-wide catalog and database on tsunamis and tsunami-like events that covers the period from 2000 $\mathrm{BC}$ to the present (Gusiakov 2003). It currently contains nearly 2,250 historical events with 1,206 of these located in the Pacific, 263 in the Atlantic, 125 in the Indian Ocean, and 545 from the Mediterranean Sea. The geographical distribution and intensity of the tsunamis are shown in Fig. 1. Most of the tsunamis were generated along subduction zones and the major plate boundaries in the Pacific, Atlantic and Indian Oceans and in the Mediterranean region. Very few historical events occurred in the deep ocean or central parts of the marginal seas, except several cases of small tsunamis that originated along the middle-ocean ridges and some major transform faults.

Most oceanic tsunamis (up to $75 \%$ of all historical cases) reported in historical catalogs are generated by shallow-focus earthquakes capable of transferring sufficient energy to the overlying water column to generate significant waves at the shore. The rest are due to landslide (7\%), volcanic (5\%), meteorological (3\%) events and to water waves from explosions (less than $1 \%)$. Up to $10 \%$ of all the reported coastal run-ups still have an unidentified source (Gusiakov 2009).

All destructive tsunamis can be divided into two categories: local (or regional) and trans-oceanic. For local tsunamis, the destructive effect is confined to the nearest coast (from 100 to $500 \mathrm{~km}$ ) located within one hour of propagation. In all tsunamigenic regions of the world oceans, most damage and casualties come from local tsunamis. Far less frequent but potentially much more hazardous are trans-oceanic tsunamis capable of widespread destruction. Formally, this category 


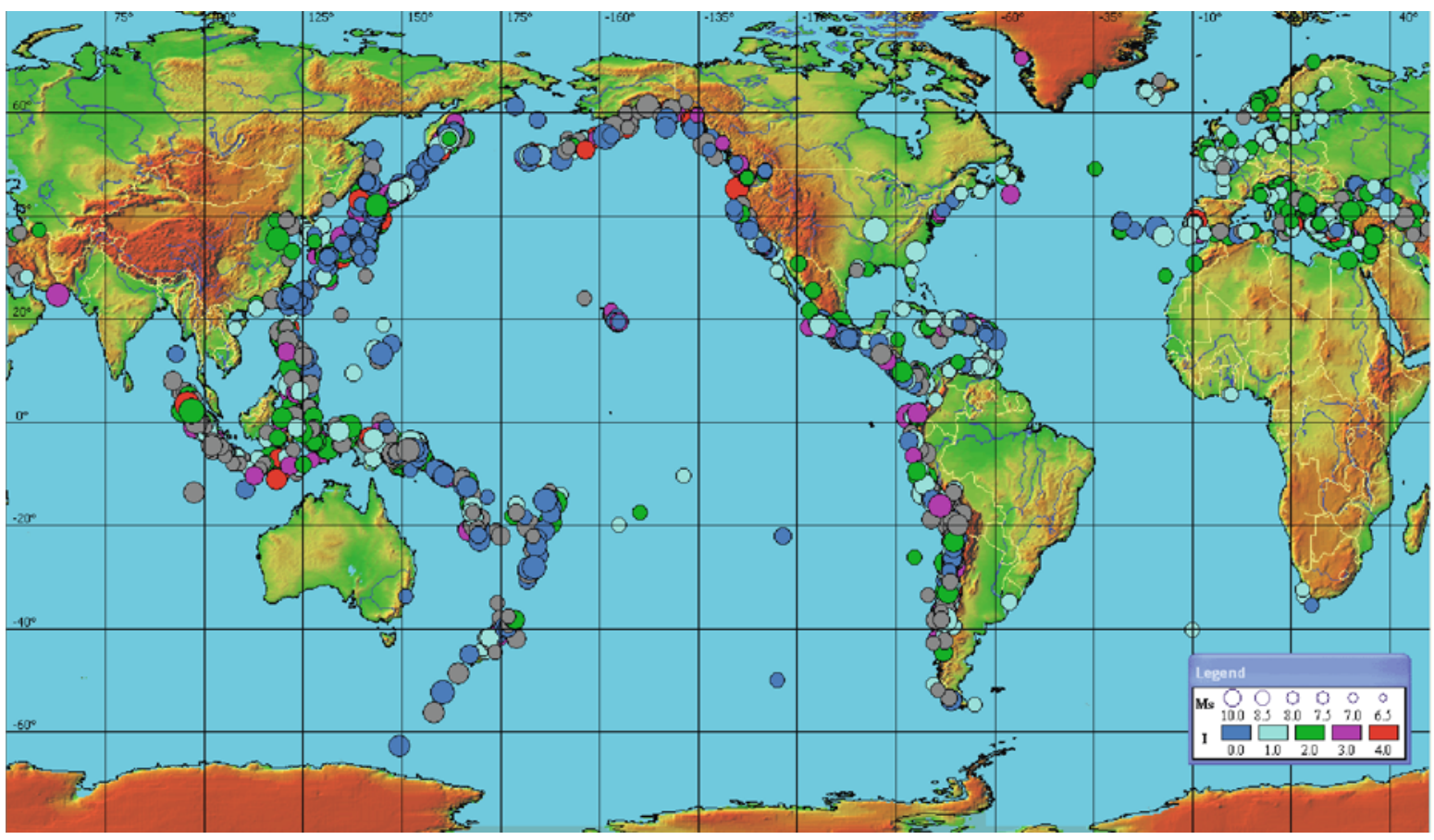

Fig. 1 Visualization of the global historical tsunami catalog. A total of 1965 tsunamigenic events with identified sources are shown for the period from 2000 BC to present time. Size of cir- cles is proportional to event magnitude (for seismically induced tsunamis); color represents tsunami intensity on the SolovievImamura scale includes the events that have run-ups higher than 5 $\mathrm{m}$ at a distance of more than $5,000 \mathrm{~km}$ from the source. Historically, all trans-oceanic tsunamis have originated in the Pacific with only two cases occurring in other regions (the 1755 Lisbon tsunami in the Atlantic and the 2004 Sumatra tsunami in the Indian Ocean). The basic parameters of the 11 known transoceanic tsunamis are listed in Table 1. By total energy, they are the largest documented tsunamigenic events, but they are not the largest ones in terms of maxi- mum run-up observed at the coast and number of fatalities. Ten of the largest regional tsunamigenic events together with their basic source parameters are listed in Table 2. All of them were highly destructive locally, and some had high rates of mortality, but they did not generate an ocean-wide tsunami.

One of the most important aspects of seismogenic tsunamis is their potential maximum run-up height in the near-field. Available historical data, summarized in Tables 1 and 2 and presented graphically in Fig. 2,
Table 1 List of historical trans-oceanic tsunamis (see text for definition).

$M$-magnitude (macroseismic, $M_{S}$ or $\left.M_{W}\right), I$-tsunami intensity on the

Soloviev-Imamura scale, $H_{\text {maxNF}}-$ maximum reported run-up in the near field in $m$, $H_{\text {maxFF-maximum reported }}$ run-up in the far field (more than $5,000 \mathrm{~km}$ ) in $\mathrm{m}$, FAT-number of reported fatalities due to tsunami

\begin{tabular}{lllccl}
\hline Date and place & $M_{S}$ & $I$ & $H_{\operatorname{maxNF}}, \mathrm{m}$ & $H_{\operatorname{maxFF}}, \mathrm{m}$ & FAT \\
\hline 1 November 1755, Lisbon & 8.5 & 4.0 & 30.0 & 7.0 & 30,000 \\
7 November 1837, Chile & 8.5 & 3.0 & 8.0 & 6.0 & many \\
13 August 1868, Chile & 9.1 & 3.5 & 15.0 & 5.5 & 612 \\
15 June 1896, Sanriku & 7.4 & 3.8 & 38.2 & 5.5 & 27,122 \\
3 February 1923, Kamchatka & 8.3 & 3.5 & 8.0 & 6.1 & 3 \\
1 April 1946, Aleutians & 7.9 & 4.0 & 42.2 & 20.0 & 165 \\
4 November 1952, Kamchatka & 9.0 & 4.0 & 18.0 & 9.1 & $>10,000$ \\
9 March 1957, Aleutians & 9.1 & 3.5 & 22.8 & 16.1 & none \\
22 May 1960, Chile & 9.5 & 4.0 & 15.2 & 10.7 & 1,260 \\
28 March 1964, Alaska & 9.2 & 4.5 & 68.0 & 4.9 & 221 \\
26 December 2004, Sumatra & 9.3 & 4.5 & 50.9 & 9.6 & 229,866 \\
\hline
\end{tabular}


Table 2 List of some of the largest regional seismogenic tsunamis in the historical catalogs. $M_{S}-$ surface wave magnitude,

$M_{W}$-moment-magnitude, I-tsunami intensity on the Soloviev-Imamura scale, $H_{\text {max }}$-maximum reported run-up in m, CAU-cause of tsunami (T-tectonic, L-landslide), FAT-number of reported fatalities due to tsunami

\begin{tabular}{lllllll}
\hline Date and Place & $M_{S}$ & $M_{W}$ & $I$ & $H_{\max }, \mathrm{m}$ & CAU & FAT \\
\hline 9 July 1586, Lima, Peru & 8.5 & - & 3.5 & 26.0 & $\mathrm{~T}$ & many \\
$\begin{array}{l}\text { 31 January 1605, Shikoku, } \\
\quad 8.0\end{array}$ & - & 3.5 & 30.0 & $\mathrm{~T}$ & many \\
$\quad$ Japan & & & & & & \\
2 December 1611, Sanriku, & 8.1 & - & 4.0 & 25.0 & $\mathrm{~T}$ & 4,783 \\
$\quad$ Japan & & & & & & \\
28 October 1707, Nankaido, & 8.1 & - & 4.0 & 25.7 & $\mathrm{~T}$ & 30,000 \\
$\quad$ Japan & & & & & & \\
23 December 1854, Nankaido, & 8.3 & - & 3.0 & 28.0 & $\mathrm{~T}$ & 5,000 \\
$\quad$ Japan & & & & & & \\
15 June 1896, Sanriku, Japan & 7.4 & 8.5 & 3.8 & 38.5 & $\mathrm{~T}$ & 27,122 \\
2 March 1933, Sanriku, Japan & 8.3 & 8.6 & 3.5 & 29.3 & $\mathrm{~T}$ & 3,064 \\
9 July 1956, Aegean Sea & 7.5 & 7.7 & 3.0 & 30.0 & $\mathrm{TL}$ & none \\
12 December 1992, Flores Sea & 7.6 & 7.7 & 2.7 & 26.2 & $\mathrm{TL}$ & 2,200 \\
12 July, 1993, Okushiri, Japan & 7.6 & 7.7 & 3.1 & 31.7 & $\mathrm{~T}$ & 198 \\
$\quad$
\end{tabular}

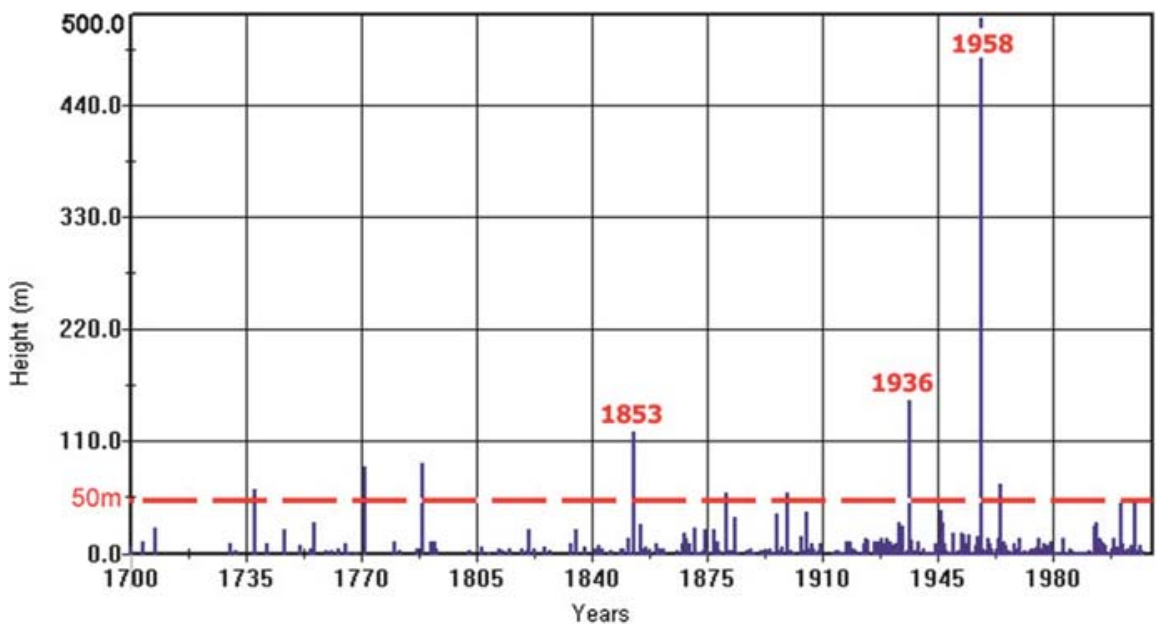

Fig. 2 Maximum run-up heights observed at the nearest coast for historical tsunamis during the last 300 years

suggests that this value cannot exceed $35-50 \mathrm{~m}$ even for the largest possible submarine earthquakes. Maximum run-up values of 60-70 m reported for the 1771 Ishigaki, 1788 Sanah-Kodyak, and 1737 Kamchatka tsunamis are not very reliable. They are based on single anecdotal reports, which are not always confirmed by recent geological investigation (see, e.g. Pinegina and Bourgeois 2001), and may have been produced by a locally generated landslide accompanying the main tectonic tsunami. As demonstrated for the 1964 Alaska earthquake, all the major run-ups that exceeded 25-30 $\mathrm{m}$ along the Alaskan coast were generated by slides from the fronts of the local deltas. These waves arrived at the coast almost immediately after the earthquake and were followed by the main seismically-induced tsunami that typically had a height of 12-18 m (Lander 1996)

Slide-generated tsunamis result from rock and ice falling into the water, and sudden submarine landslides or slumps. They can produce extremely high water splash along a coastline, up to 50-70 m, with the highest historical record being $525 \mathrm{~m}$ in Lituya Bay, Alaska in 1958. In general, the impact is not widely extended along the coast. The energy of a landslidegenerated tsunami rapidly dissipates as waves travel away from the source. However, in some cases, if the landslide covers a large depth range or occurs over a long duration of slide movement, it can focus the tsunami energy into a beam narrower than the equivalent seismic source (Iwasaki 1997). 
Based on analysis of available historical data, we can conclude the following: (1) tsunami run-ups generated by the largest possible seismogenic and volcanic events rarely exceed $45-50 \mathrm{~m}$ at the nearest coast and 15-20 m run-up in the far-field, and (2) landslidegenerated tsunamis can be highly destructive locally, but never flood any extended part of the coast.

It is therefore of considerable interest that the world's coastlines contain prominent erosional and depositional features of catastrophic water currents and waves of much higher magnitude over wide areas.

\section{Erosional and Depositional Traces of Large-Scale Water Impact on the Coast}

The most common signature of tsunami is the deposition of landward tapering sandy units up to 50-cmthick sandwiched between finer material and peats on flat coastal plains. While similar lenses can be deposited by individual surging waves during tropical cyclones, such units are rarely longer than 10-20 m and do not form continuous deposits behind modern beaches. Tsunami sand units form part of a coherent landward thinning splay of fining sediment extending up to $10 \mathrm{~km}$ or more inland. The thickness of laminae decreases landward while that of an individual unit decreases upwards, implying waning energy conditions. All these characteristics match transport of sediment-rich flows by tsunami across marsh surfaces. Anomalous sand layers can have an erosional basal contact and incorporate rip-up clasts of muddier sediment.

The emphasis on sand units as a signature of tsunami ignores other depositional phenomena namely the transport and imbrication of boulders. The clearest evidence of this is the movement of large boulders onshore (Bryant 2008). For example, the Sea of Japan tsunami of 26 May 1983 produced a tsunami over $14 \mathrm{~m}$ high. A large block of concrete weighing over 1,000 tons was moved $150 \mathrm{~m}$ from the beach over dunes $7 \mathrm{~m}$ high. Boulders transported by tsunami have also been found in paleo-settings. For example, on the reefs of Rangiroa, Tuamoto Archipelago in the Southeast Pacific, individual coral blocks measuring up to $750 \mathrm{~m}^{3}$ have been linked to tsunami rather than to storms. On Hateruma and Ishigaki Islands in the
South Ryukyu Islands, coralline blocks measuring 100 $\mathrm{m}^{3}$ have been emplaced $30 \mathrm{~m}$ above present sea level, $2.5 \mathrm{~km}$ from the nearest beach (Kawana and Nakata 1994). These boulders have been dated and indicate that tsunamis with a local source, have washed over the islands seven times in the last 4,500 years. Two of the largest events occurred 2,000 years ago and during the great tsunami of 24 April 1771. In the Leeward Islands of Netherlands Antilles in the Caribbean, boulders weighing up to 280 tons have been moved 100 $\mathrm{m}$ by repetitive tsunamis most likely occurring 500 , 1,500 and 3,500 years ago (Scheffers 2004). In fact, detailed cataloging of anomalous boulders from the literature indicates that they are the prevalent signatures of tsunami events on most coasts (Kelletat 2008).

\section{Australian Imbricated Boulder Fields, Cavitation, and Vortex Structures}

Along the East Coast of Australia, anomalous boulders are incompatible with the storm wave regime (Bryant 2008). For example, exposed coastal rock platforms along this coast display little movement of boulders up to 1-2 $\mathrm{m}$ in diameter, despite the presence of 7to 10-m-high storm waves. Boulders are also found in completely sheltered locations along the coast. At Bass Point, which extends $2 \mathrm{~km}$ seaward from the coast, a boulder beach faces the mainland coast rather than the open sea. Similarly at Haycock Point, rounded boulders, some with volumes of $30 \mathrm{~m}^{3}$ and weighting 75 tons, have been piled into a jumbled mass at the base of a ramp that begins $7 \mathrm{~m}$ above a vertical rock face on the sheltered side of the headland. Perhaps the most dramatic deposits are those containing piles of imbricated boulders (Fig. 3). These piles take many forms, but include boulders up to $105 \mathrm{~m}^{3}$ in volume and weighing as much as 285 tons. The boulders lie en echelon one against the other like fallen dominoes, often in parallel lines. At Jervis Bay, New South Wales, blocks weighing almost 100 tons have clearly been moved in suspension and deposited in this fashion above the limits of storm waves on top of cliffs $33 \mathrm{~m}$ above present sea level. The longest train of imbricated boulders exists at Tuross Head where 2-to 3-m-diameter boulders stand as sentinels one against the other, over a distance of $200 \mathrm{~m}$ at an angle to the coast (Young et al. 1996). 


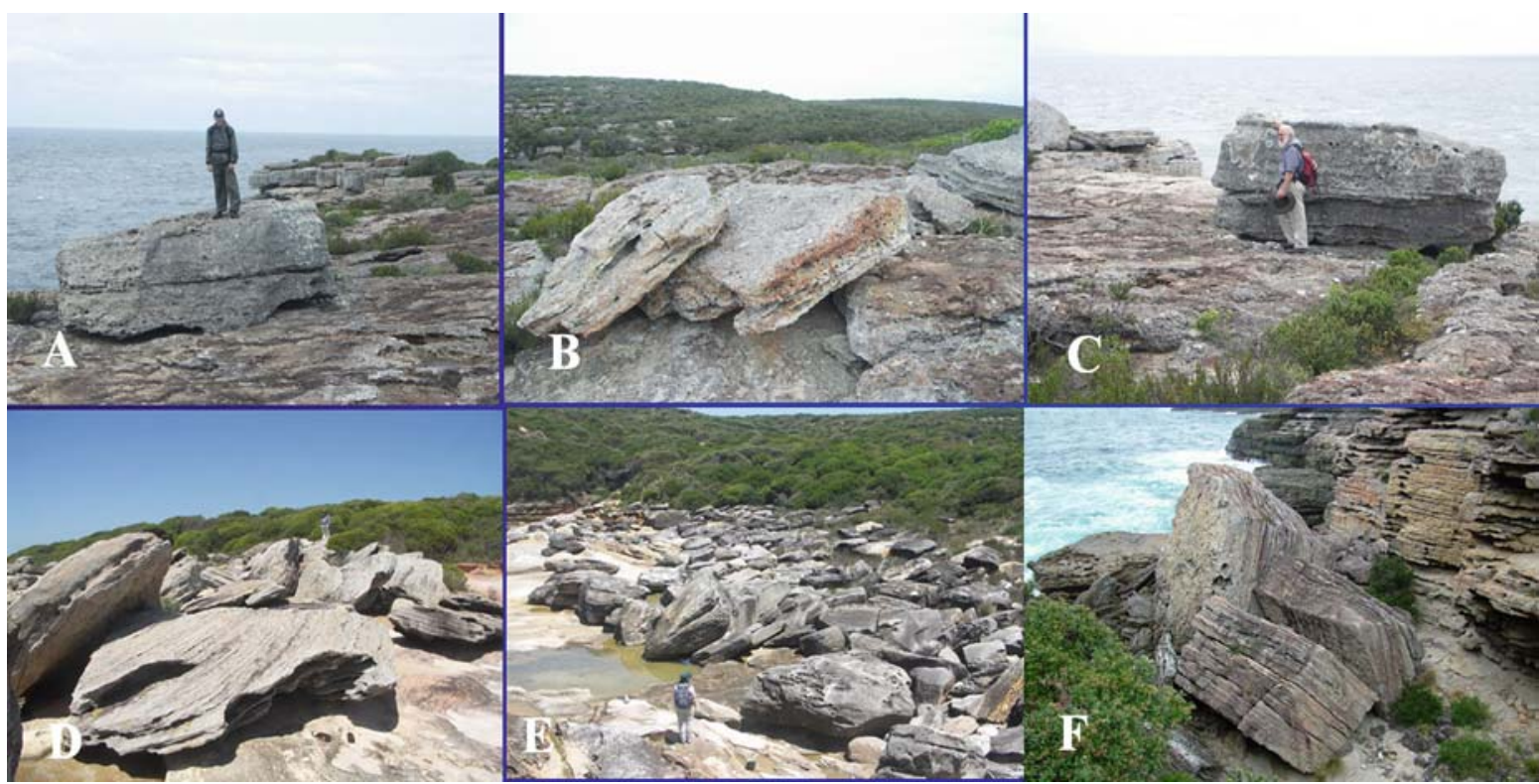

Fig. 3 Massive imbricated boulders at height of up to $40 \mathrm{~m}$ on the southeastern coast of Australia

Tsunamis can also sculpture bedrock in a fashion analogous to the s-forms produced by high velocity catastrophic floods or surges from beneath icecaps in sub-glacial environments (Kor et al. 1991). S-forms include features such as muschelbrüche, sichelwannen, V-shaped grooves, cavettos, and flutes. They have been linked to paleo-floods in Canada, the northwestern United States, Scandinavia, Britain, the Alps, and the Northern Territory, Australia. Tsunami flows at velocities above $10 \mathrm{~m} / \mathrm{s}$ have the hydrodynamic potential over rocky headlands to generate cavitation or small vortices capable of producing sculptured forms. Cavitation is a product of high-velocity flow as great as $10 \mathrm{~m} / \mathrm{s}$ in water depths as shallow as $2 \mathrm{~m}$ deep (Baker 1981). At these velocities, small, low pressure, air bubbles appear in the flow. These bubbles are unstable and immediately collapse, generating impact forces up to thirty thousand times greater than normal atmospheric pressure. Cavitation bubble collapse is highly corrosive. Cavitation features generated by mega tsunami are widespread along the New South Wales coast of eastern Australia and consist of impact marks, drill holes, and sinuous grooves (Bryant 2008). The spatial organization of s-forms on headlands, often above the limits of storm waves, is a signature of tsunami in the absence of any other definable process (Bryant and Young 1996). Impact marks appear as pits or radiating star-shaped grooves on vertical faces facing the flow. It would be simple to suggest that such features represent the impact mark of a rock hurled at high velocity against a vertical rock face; however, such marks have also been found in sheltered positions or tucked into undercuts where such a process is unlikely (Fig. 4f). Drill holes are found over a range of locations on tsunami-swept headlands (Fig. 4e). Their distinguishing characteristic is a pit several centimeters in diameter bored into resistant bedrock. While it would be easy to attribute these features to marine borers, they often occur profusely above the limit of high tide.

The term flute describes long linear forms that develop under unidirectional, high-velocity flow in the coastal environment. These are noticeable for their protrusion above, rather than their cutting below, bedrock surfaces (Fig. 4d). In a few instances, flutes taper downstream and are similar in shape to rock drumlins and rattails described for catastrophic flow in subglacial environments (Kor et al. 1991). In all cases, the steeper end faces the tsunami wave, while the spine is aligned parallel to the direction of tsunami flow. Flutes span a range of sizes, increasing in length to $30-50 \mathrm{~m}$ as slope decreases. However, their relief rarely exceeds $1-2 \mathrm{~m}$.

On flat surfaces, longitudinal vortices give way to vertical ones that can form potholes (Fig. 4b, c,e). 


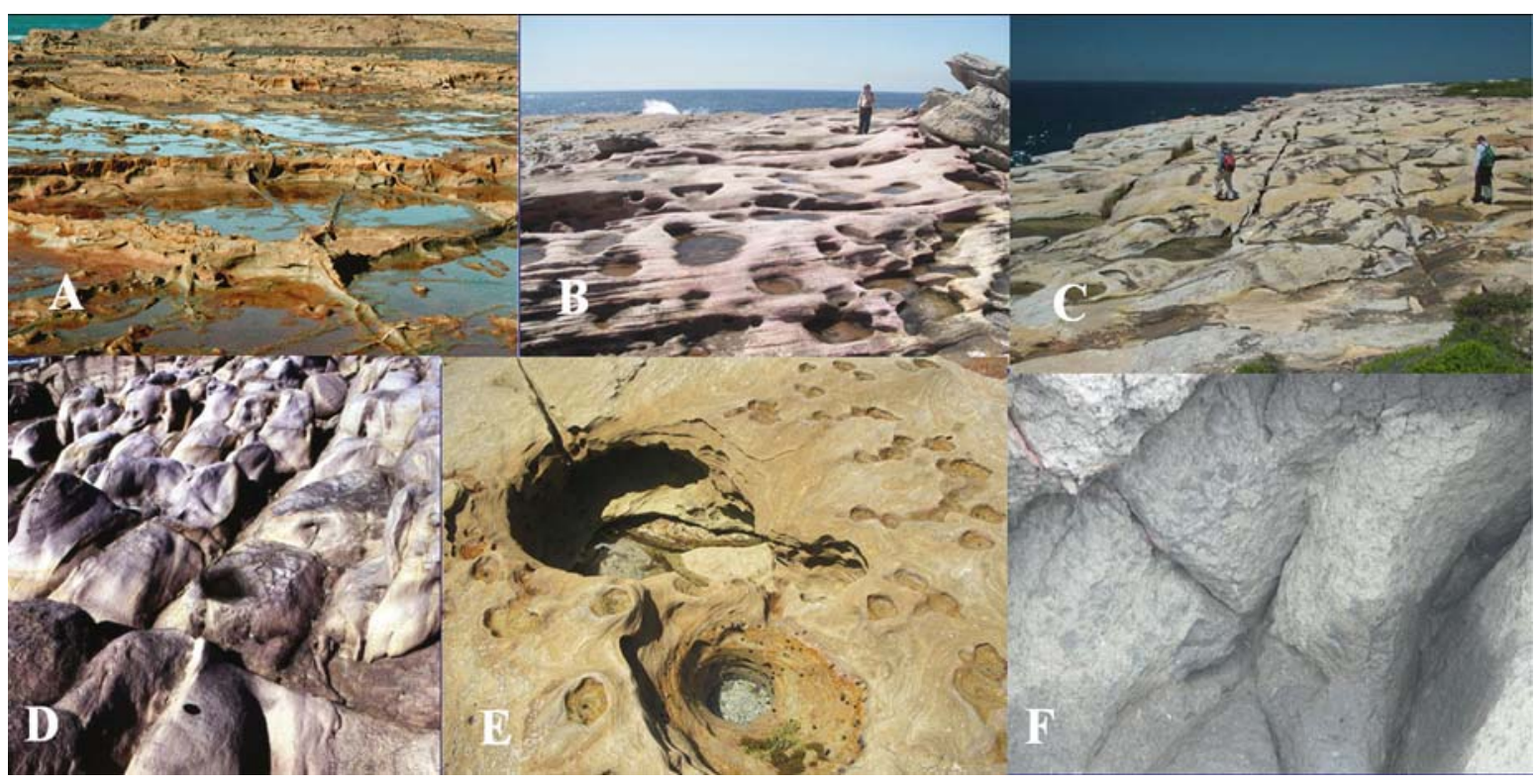

Fig. 4 Different forms of sculptured bedrock along the southeastern Australian coast. They are believed to be a result of cavitation and/or impact of high velocity water currents

Potholes are usually attributed to mechanical abrasion under normal ocean wave action; however many exhibit features of high velocity flow. They form at different scales from forms up to $70 \mathrm{~m}$ in diameter to smaller features with dimensions of 4-5 m. The potholes tend to develop as flat-floored, steepwalled rectangular depressions, usually within the zone of greatest turbulence. While bedrock jointing may control this shape, a pothole's origin as a bedrocksculptured feature is unmistakable where the inner walls are inevitably undercut or imprinted with cavettos. In places where vortices have eroded the connecting walls between potholes, a chaotic landscape of jutting bedrock with a relief of 1-2 $\mathrm{m}$ can be produced (Fig. 4b, e). This morphology - termed hummocky topography - forms where flow is unconstrained and turbulence is greatest. These areas occur where highvelocity water flow has changed direction suddenly, usually at the base of steep slopes or on the seaward crest of headlands. In the latter case, they can be situated well above sea level and the effects of windgenerated waves (Fig. 4b, e).

Large-scale features can usually be found sculptured or eroded on rock promontories, which protrude seaward onto the continental shelf (Bryant 2008). Such features require extreme run-up velocities that can only be produced by the higher or longer waves (mega tsunami) generated by large submarine landslides or asteroid impacts in the ocean. One of the most common features of high-velocity overwashing is the stripping of joint blocks from the fronts of cliffs or platforms forming inclined surfaces or ramps (Fig. 4d). In many cases, this stripping is aided by the detachment of flow from surfaces, a process that generates enormous lift forces that can pluck joint-controlled rock slabs from the underlying bedrock. Where standing waves have formed, bedrock plucking can remove two or three layers of bedrock from a restricted area, leaving a shallow, closed depression on the ramp surface devoid of rubble and unconnected to the open ocean. Ramps are obviously controlled structurally and have an unusual juxtaposition beginning in cliffs up to $30 \mathrm{~m}$ above sea level and sloping down flow, often into a cliff. If these high velocities are channelized, erosion can produce linear canyon features 2-7 $\mathrm{m}$ deep and pool-and cascade features incised into resistant bedrock on the lee side of steep headlands (Fig. 4c, e).

Perhaps the most impressive features are whirlpools formed in bedrock on the sides of headlands. Whirlpools and smaller potholes are commonly formed under catastrophic flow in the channeled scabland of Washington State. In coastal environments, whirlpools often contain a central plug of rock and show evidence of smaller vortices around their rim. 


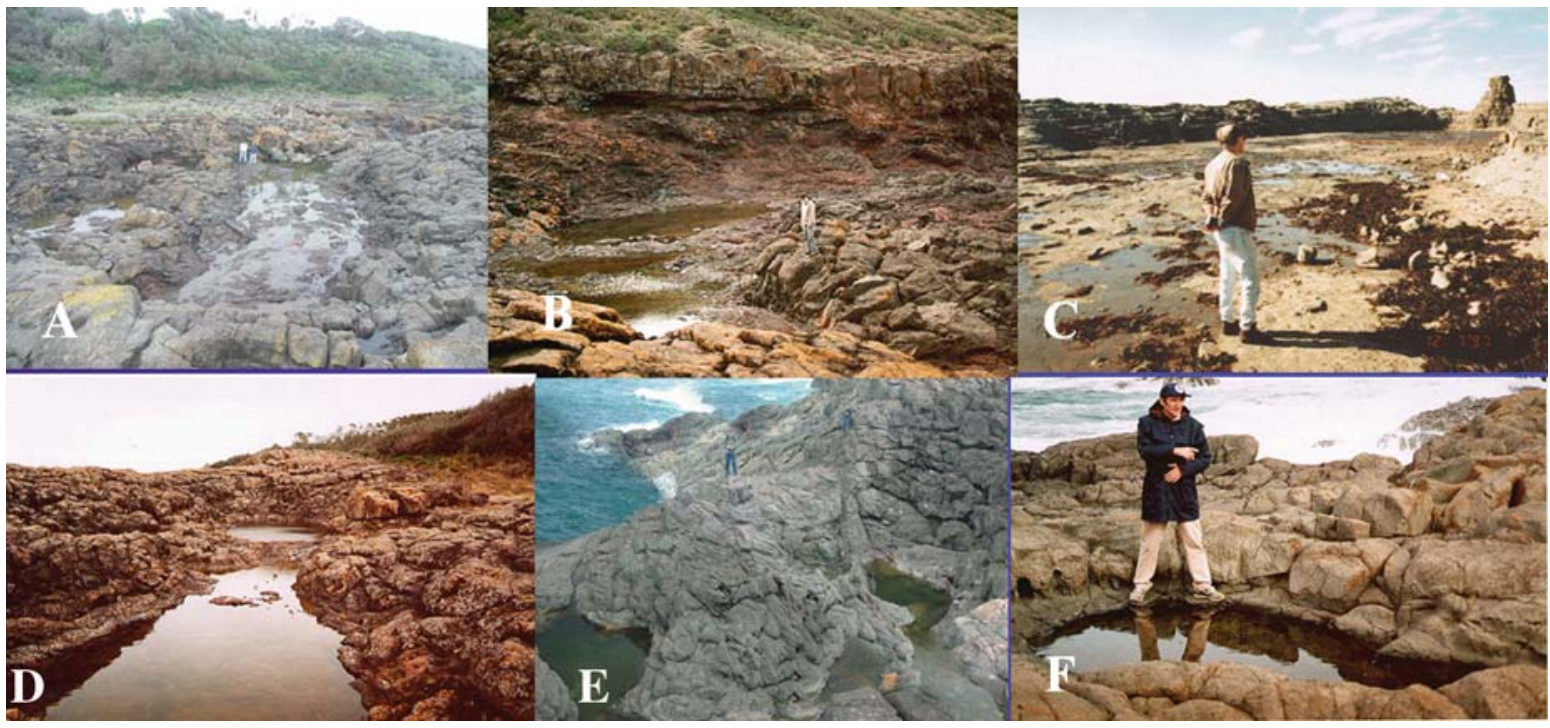

Fig. 5 Vortex structures along the Australian SE coast. They are believed to be carved into resistant coastal rocks by water currents with velocity $\mathrm{V}>10 \mathrm{~m} / \mathrm{s}$ and depth $\mathrm{D}>5 \mathrm{~m}$. Cavitation is also involved in the erosional process

Whirlpools can reach $50-70 \mathrm{~m}$ in diameter with central plugs protruding $2-3 \mathrm{~m}$ vertically upwards from the floor of the pit at the quiescent centre of the vortex (Fig. 5b, e). One of the best examples occurs on the south side of Atcheson Rock south of Bass Point, New South Wales (Fig. 5e). Here a large vortex, spinning in a counterclockwise direction, produced smaller vortices rotating around its edge on the up flow side of a headland. The overall whirlpool is $10 \mathrm{~m}$ wide and 8-9 $\mathrm{m}$ high. The central plug stands $5 \mathrm{~m}$ high and is surrounded by four 3-m-diameter potholes, one of which bores another $3 \mathrm{~m}$ below the floor of the pit into resistant basalt. The counterclockwise rotation of the overall vortex produces downward-eroded helical spirals that undercut the sides of the pit, forming spiral benches. Circular or sickle-shaped holes were drilled, by cavitation, horizontally into the sides of the pothole and into the wall of the plug. Under exceptional circumstances, the whirlpool can be completely eroded, leaving only the plug behind (background of Fig. 5c).

\section{Chevron Dunes}

Many coastlines of the world exhibit sets of large Vshaped chevron-like dunes - symmetrical sand dunes that are similar in their lancet-form, showing strong parallelism, often at different angles to the shoreline
(Bryant 2001; Kelletat and Scheffers 2003). Some typical examples of chevron dunes from different parts of the world are shown in Fig. 6. The term "chevron" was first used to describe wind-blown dunes by Maxwell and Haynes (1989) in south-western Egypt and northern Sudan, where the chevrons consist of sinuous, parallel, blade-shaped deposits of sand $10-30 \mathrm{~cm}$ high and $0.13-1.2 \mathrm{~km}$ in length which actively migrate over darker coarse sands. Hearty et al. (1998) and Kindler and Strasser (2000) applied this term to coastal dunes. They used this term in the Bahamas to describe nested parabolic shaped dunes formed during the Last Interglacial age and attributed them to megastorm deposits. Bryant (2001) recognized that certain coastal chevrons could be formed by megatsunamis because their limits are far above those of any storm surges reported in the literature. Only dominant winds or high-energy water currents can be responsible for the formation of chevrons. In this paper, we do not limit the term "chevron" to any one process but use it in the broadest sense to refer to any sedimentary feature within the coastal landscape with this distinctive V-shaped morphology.

Since Google Earth satellite imagery become available in early 2005, a wide distribution of chevrontype geomorphologic features along many coastlines of the world (Fig. 7) was quickly identified (Scheffers et al. 2008). Actually, they can be found at almost 


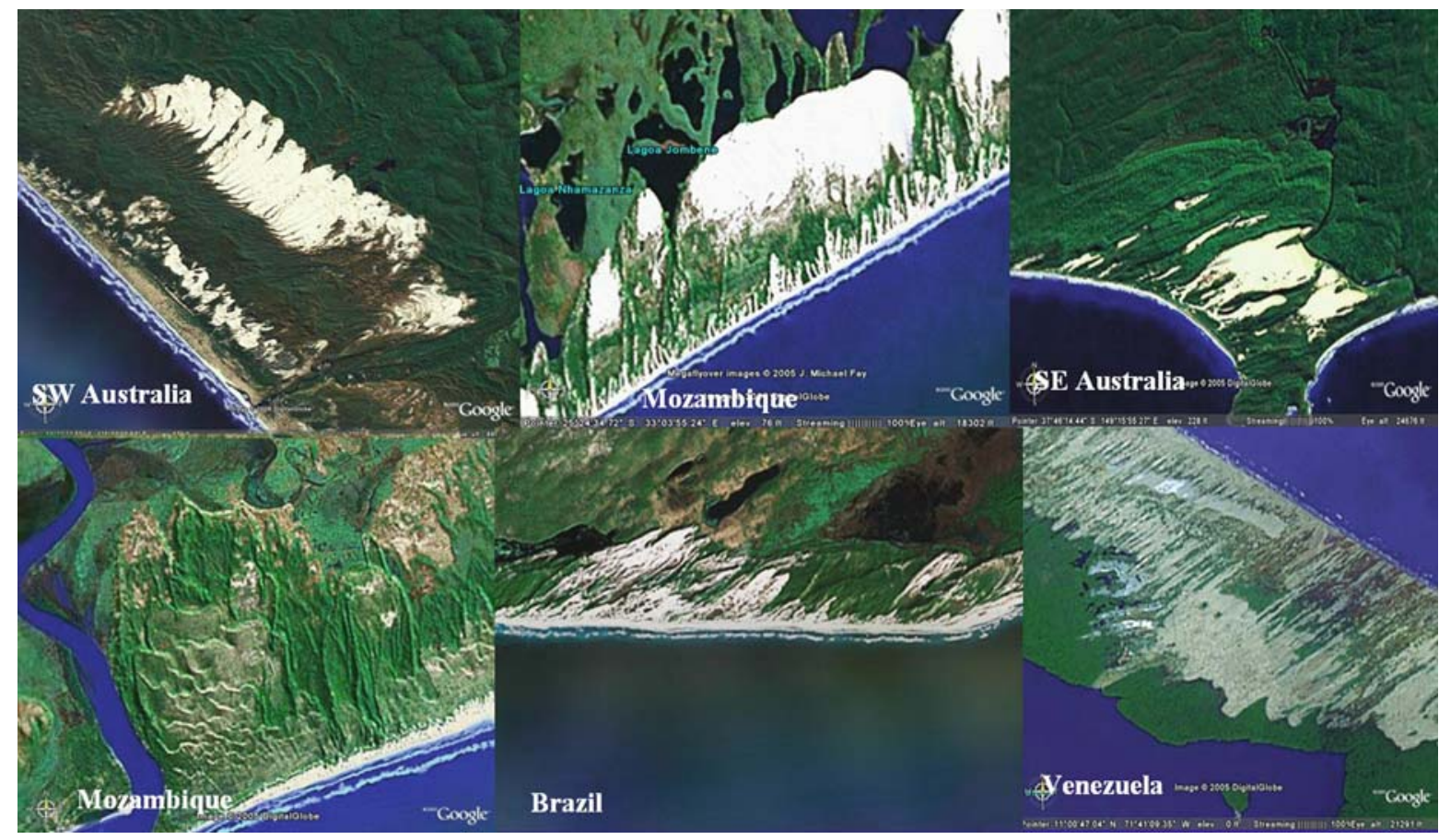

Fig. 6 Examples of chevron dunes from different coastlines of the world. They reach heights of more than $100 \mathrm{~m}$ with inland impact of destructive oceanic waves with possible later modifipenetration of up to $10 \mathrm{~km}$ and are believed to be a result of

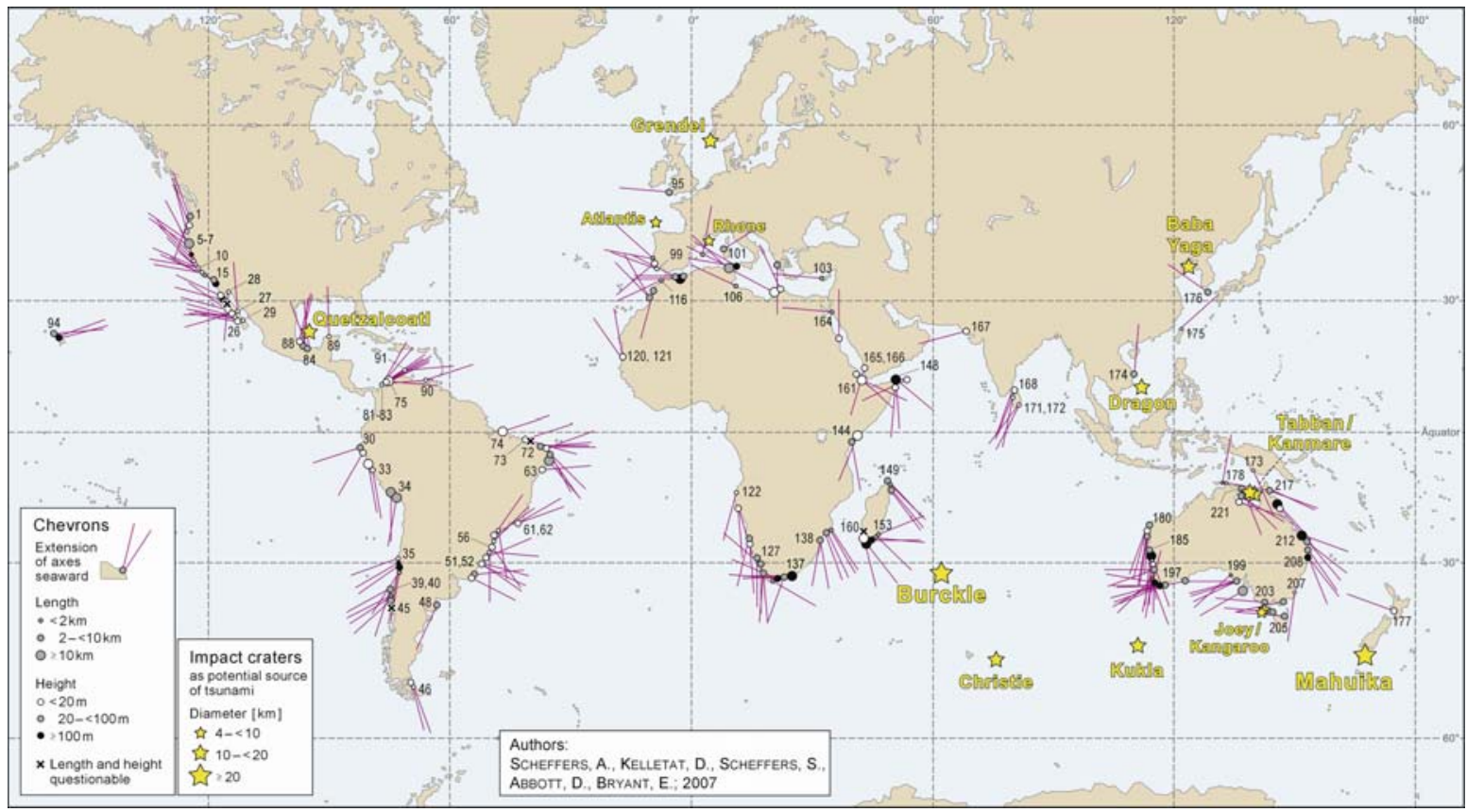

Fig. 7 Location map and orientation of chevron dunes identified on satellite images (Scheffers et al., 2008) 
any undisturbed coast having sufficient sand supply from beaches and shallow water areas. On aerial photographs and satellite images chevrons appear as light colored areas with fresh sand and sparse vegetation. But in many places, they are densely covered by vegetation indicating an older age. An important feature of coastal chevrons is that they consist of unsorted marine sand and quite often contain fist-sized cobbles, pieces of coral rock and mud clasts. In some cases, they are not aligned to the dominant wind direction.

Obviously, some chevrons, or parts of them, have undergone a partial remobilization of sand by wind with formation of superimposed dunes of different shapes: parabolic, irregular or barchan types. The total length of chevrons, i.e. their landward extension, clearly depends upon coastal topography. Where the coast is flat, larger chevrons may occur. Coastal lowlands with wide beaches are the best source areas for long chevrons, but they also exist along cliffed coasts, where there is no visible source of available sand (Scheffers et al. 2008).

The most spectacular chevrons on the planet are found at the southernmost tip of Madagascar where they reach heights of more than $200 \mathrm{~m}$ above present sea level with inland penetration of up to $45 \mathrm{~km}$. Other impressive examples of coastal chevrons are located along the coast of the Gulf of Carpentaria in northern Australia. The Madagascar and Carpentaria chevrons are discussed below in sections devoted to the hypothesized Burckle and Carpentaria impacts.

\section{Cosmic Impact Implications of Coastal Erosional and Depositional Features}

As we see from the above, many world ocean coastlines contain prominent features of catastrophic modification by water currents and waves that came from the ocean. The measured run-up heights (100-200 m) and inland penetration (tens of kilometers) over the extended part of the coast are far beyond the range produced by the largest historically known tectonic tsunamis (seismic and volcanic). Such large magnitude run-ups can be produced only by a large-volume submarine landslide or by oceanic impacts. In the latter case, the impacts may also be responsible for major environmental downturns during the Holocene that have been indicated by environmental reconstructions using tree-ring records, lake-bottom sediments analysis and ice-core data.

\section{The Search for Quaternary and Holocene Period Cosmic Impacts}

Our team's search for recent Earth impact events involves different tools depending on the likely target area (oceanic versus terrestrial), relative size of the impactor, estimated age of the event (Holocene vs. Quaternary period), and whether the impactor was an asteroid or comet. For oceanic impacts, we use satellite altimetry along with the search for coastal tsunami sedimentary signatures and the presence of impact indicators in deep sea and coastal sediment cores, such as ejecta and layers of high magnetic susceptibility. For middle and late Holocene impacts, we have discovered a treasure trove of information on the nature and dates of impacts in oral traditions and mythologies (e.g. Masse 2007; Masse and Masse 2007; Bryant et al. 2007). And recently, we have begun to realize that larger impacts may be signaled by substantive changes in the Earth's paleoclimate.

The Tsunami Laboratory in Novosibirsk, Russia, has compiled and is maintaining an Expert Database on Earth Impact Structures (EDEIS, http://tsun.sscc.ru/nh/impact.php), which is somewhat more liberal than the well-known Earth Impact Database maintained by the Planetary and Space Science Centre, University of New Brunswick, Canada (http://www.unb.ca/passc/ImpactDatabase/index.html). In addition to including the fully validated impact structures, the EDEIS lists also proposed structures whose impact genesis still needs validation. For any structure, the degree of confidence of impact origin is reflected by its validity index $\mathrm{V}$, which varies from 4 (apparently confirmed) to 0 (rejected) with intermediate values of 3 (probable), 2 (possible) and 1(supposed). The validity index reflects availability of four different set of impact criteria - morphological (circular form, presence of edge wall, inconsistency with local geological settings), petrologic (signs of shock metamorphism), mineralogical (presence of high pressure minerals, PDF structures, etc.) and chemical (presence of extraterrestrial elements and materials). Currently, the database contains 905 structures with 206 of them having $V=4,200$ with 


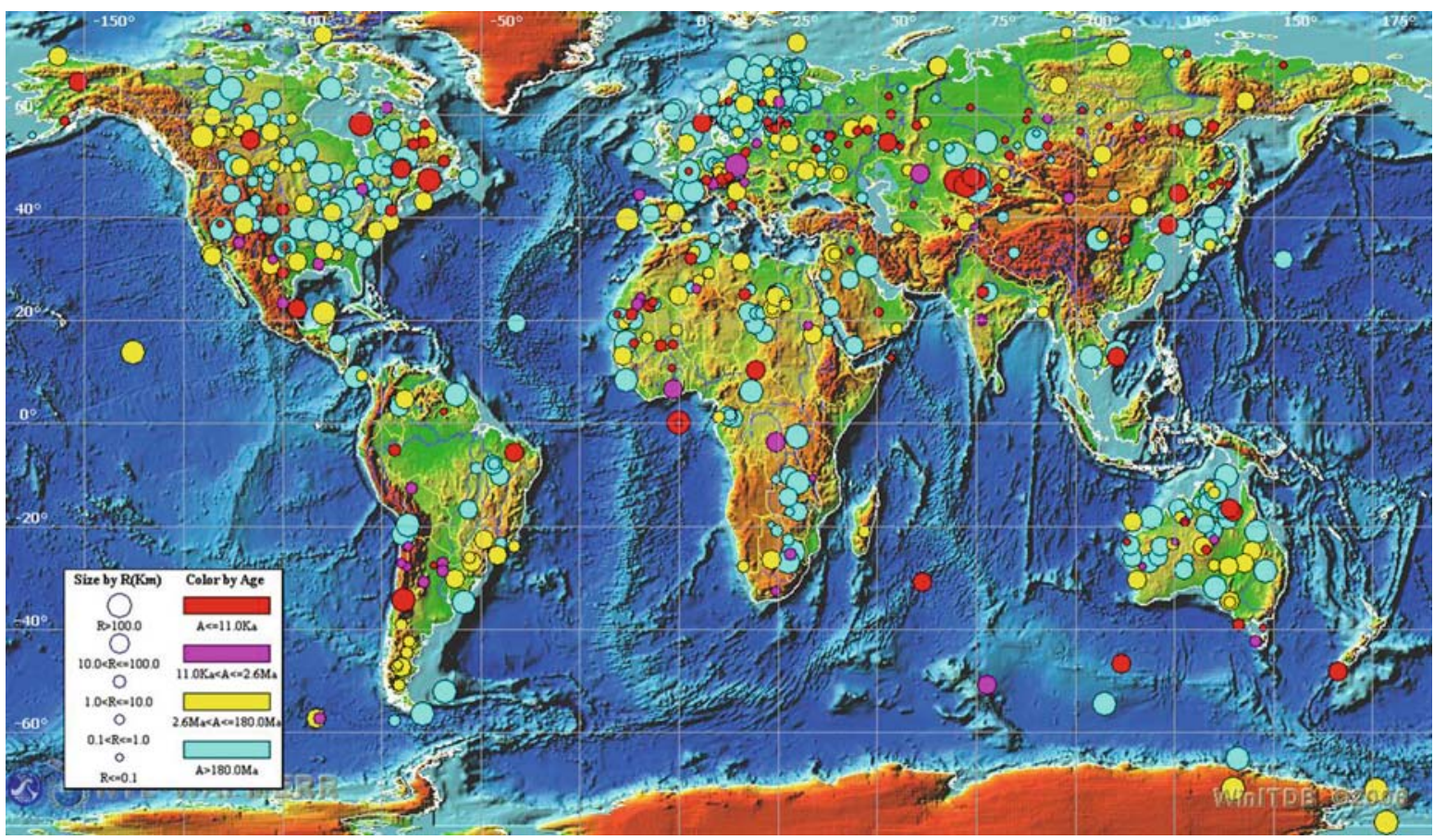

Fig. 8 Map of the Earth impact structures, divided by the age of formation (905 structures for the whole Earth history). Source of data - Expert Database on Earth Impact Structures (EDEIS, http://tsun.sscc.ru/nh/impact.php)

$\mathrm{V}=3,391$ with $\mathrm{V}=2$ and 39 with $\mathrm{V}=1$ (Fig. 8). Sixtynine records in the database have validity index of 0 , because the proposed impact origin was disproven by additional study.

Using this index, we have identified 115 Quaternary period structures ( 38 with $\mathrm{V}=4,38$ with $\mathrm{V}=3$, 34 with $\mathrm{V}=2$ and 5 with $\mathrm{V}=1$ ) containing a subset of 57 Holocene period structures ( 19 with $V=4$, 19 with $\mathrm{V}=3,15$ with $\mathrm{V}=2$ and 4 with $\mathrm{V}=1$ ). Not all, including the $\mathrm{V}=4$ and 3 categories, will necessarily eventually be validated. For example, it could be demonstrated by future studies that mineral specimens thought to be extraterrestrial can actually be reproduced by terrestrial means, and that circular features on the seabed currently defined using satellite sea surface altimetry may prove otherwise. However, this index helps to address some of the significant information hidden or missing from standard lists of validated impact structures (e.g., Table 3) based on current statistical estimates of the rates, risks, and effects of cosmic impact.

Table 3 demonstrates clearly the problem of our current reliance on completely validated impacts by which to judge the rates and risks of cosmic impact. In partic- ular, recent so-called "globally catastrophic" impacts ( $\geq 10^{6}$ megatons $[\mathrm{Mt}]$ ), modeled to occur on average once every million years (Bobrowsky and Rickman 2007; Morrison et al. 2002; Toon et al. 1997), and even more frequent regionally catastrophic impacts (ca. $10^{3}-10^{5} \mathrm{Mt}$ ), are greatly underrepresented in such lists (Masse 2007; Masse et al. 2007). Our assumption is that the majority of such impacts would have occurred in the ocean, where only a handful of crater structures have been thus far identified, and none during the past 15 million years. Table 3 does not include known airbursts (such as the 1908 Tunguska event) or tektite fields for which a crater has not yet been definitively established. Table 3 also clearly demonstrates how smaller craters become increasingly more difficult to identify back through time.

Therefore, standard lists of validated impact structures are missing several geologically recent key impact events that could alter the manner in which scientists and planners currently model and estimate cosmic impact risks and effects. These include hypothesized impact events profoundly affecting human populations, some of which may also have been a trigger for climate change (Fig. 9). Some are previously 
Table 3 Validated impact structures during the past 15 million years. Asterisks $\left(^{*}\right)$ highlight probable regionally catastrophic impacts while the plus $\left(^{+}\right)$signify a globally catastrophic impact

\begin{tabular}{|c|c|c|c|}
\hline $\begin{array}{l}\text { Impact structure } \\
\text { name }\end{array}$ & $\begin{array}{l}\text { Location of impact } \\
\text { structure }(\text { terrestrial }= \\
\mathrm{T} ; \text { oceanic }=\mathrm{O})\end{array}$ & $\begin{array}{l}\text { Diameter in km of largest } \\
\text { crater (and number of } \\
\text { known associated craters) }\end{array}$ & $\begin{array}{l}\text { Estimated date of } \\
\text { impact ca. Years before } \\
\text { present (ad 2009) }\end{array}$ \\
\hline Sikhote alin & Russia (T) & $0.027(122)$ & 52 \\
\hline Wabar & Saudi Arabia (T) & $0.116(3)$ & 305 \\
\hline Sobolev & Russia (T) & $0.053(1)$ & $<1,000$ \\
\hline Haviland & United States $(\mathrm{T})$ & $0.015(1)$ & $<1,000$ \\
\hline Kaalijärv & Estonia (T) & $0.110(9)$ & $2,400-2,800 ?$ \\
\hline Campo del cielo & Argentina $(\mathrm{T})$ & $0.050(20)$ & $4,200-4,700$ \\
\hline Henbury & Australia (T) & $0.157(11)$ & $<4,700$ \\
\hline Rio cuarto & Argentina $(\mathrm{T})$ & $4.500(11)$ & $4,500-5,000$ \\
\hline Macha & Russia (T) & $0.300(1)$ & $<7,000$ \\
\hline Ilumetsa & Estonia (T) & $0.080(3)$ & $7,400-7,700$ \\
\hline Morasko & Poland (T) & $0.100(8)$ & $<10,000$ \\
\hline Tenoumer & Mauritania (T) & $1.900(1)$ & 21,400 \\
\hline Barringer & United States (T) & $1.186(1)$ & 49,000 \\
\hline Odessa & United States (T) & $0.168(7)$ & $<50,000$ \\
\hline Lonar & India $(\mathrm{T})$ & $1.830(1)$ & 52,000 \\
\hline Boxhole & Australia (T) & $0.170(1)$ & 54,000 \\
\hline Amguid & Algeria (T) & $0.450(1)$ & $<100,000$ \\
\hline Tswaing & South africa $(\mathrm{T})$ & $1.130(1)$ & 220,000 \\
\hline Kalkkop & South africa $(\mathrm{T})$ & $0.640(1)$ & $<250,000$ \\
\hline Dalgaranga & Australia (T) & $0.024(1)$ & 270,000 \\
\hline Wolfe creek & Australia (T) & $0.080(1)$ & $<300,000$ \\
\hline *Zhamanshin & Kazakhstan $(\mathrm{T})$ & $14.000(1)$ & 900,000 \\
\hline Veevers & Australia (T) & $0.080(1)$ & $<1,000,000$ \\
\hline Monturaqui & Chile (T) & $0.460(1)$ & $<1,000,000$ \\
\hline *Bosumtwi & Ghana $(\mathrm{T})$ & $10.500(1)$ & $1,070,000$ \\
\hline New quebec & Canada (T) & $3.440(1)$ & $1,400,000$ \\
\hline Telemzane & Algeria (T) & $1.750(1)$ & $<3,000,000$ \\
\hline Aouelloul & Mauritania $(\mathrm{T})$ & $0.390(1)$ & $3,000,000$ \\
\hline *El'gygytgyn & Russia (T) & $18.000(1)$ & $3,500,000$ \\
\hline Roter kamm & Namibia (T) & $2.500(1)$ & $3,700,000$ \\
\hline${ }^{+}$Kara-kul & Tajikistan (T) & $52.000(1)$ & $<5,000,000$ \\
\hline *Karla & Russia (T) & $10.000(1)$ & $5,000,000$ \\
\hline Bigach & Kazachstan $(\mathrm{T})$ & $8.000(1)$ & $5,000,000$ \\
\hline Steinheim & Germany (T) & $3.800(1)$ & $15,000,000$ \\
\hline${ }^{*}$ Ries & Germany (T) & $24.000(1)$ & $15,100,000$ \\
\hline
\end{tabular}

$\left(>10^{6} \mathrm{Mt}\right.$ ). (Adapted with minor date changes from the University of New Brunswick Earth Impact Database, December 2008: http://www.unb.ca/passc/ImpactDatabase) known and have been the subject of much study, such as the large Australasian strewn tektite field event (ca. 800,000 years BP) and Eltanin (ca. 2,615 million years BP), for which craters have not yet been identified (Masse 2007). Others, more controversial, include Burckle crater ("Flood Comet" event ... see Abbott et al. 2005; Masse 1998, 2007) that may be associated with worldwide stories of a Great Flood (Noah's Flood) and the boundary change from middle to late Holocene around 4,800 years BP; the Tabban and Kanmare structures that may be associated with the AD 536-545 "years without a summer" climatic event (Baillie 2007); the Rio Cuarto impact in Argentina (Schultz and Lianza 1992) that may be associated with human population replacement around 6,000 to 3,000 years BP (Masse and Masse 2007; Barrientos and Masse 2009); the Chiemgau crater field in southern Germany that may relate to cultural changes in the 1st millennium BC (http://www.chiemgauimpact.com; Masse 2007); Mahuika crater just south of New Zealand that may be related to the beginning of the Little Ice Age at around AD 1450 (Bryant 
et al. 2007); and faunal extinctions and major climatic changes and/or climate downturns during the Younger Dryas stadial event that may have been caused by an impact/airburst over the Laurentide ice sheet at around 12,900 years BP (Firestone et al. 2007). The fact that Burckle, Chiemgau, Mahuika, Tabban - Kanmare , and the Younger Dryas Event are all suggested as comet impacts is interesting - and controversial given that comets are thought to make up less than $10 \%$ of the impact risk (Bobrowsky and Rickman 2007).

Current standards for verifying the ejecta from impact craters on land are largely based on three techniques: analysis of thin sections, verification of iridium anomalies, and verification of shocked quartz. These techniques are either unsuitable or more difficult to apply in the case of abyssal impact craters. Conventional thin sections have the best quality and polish when they are made from rock fragments a centimeter or more in diameter. However, moderate sized impactors that strike an unconsolidated substrate composed of unlithified sediments do not produce cen- timeter sized rock fragments. Instead, we find glassy fragments that rarely exceed 500 micrometers $(\mu \mathrm{m})$ in diameter.

Our studies of oceanic cores indicate that glass and mineral fragments are usually very small in impacts produced by moderate-sized impactors in unconsolidated unlithified sediments. The glass and mineral fragments usually range between 63 and $250 \mu \mathrm{m}$ in diameter. These fragments can be made into thin sections but they are more altered by seawater and are more difficult to polish and to analyze by microprobe techniques. So far, we have been unable to achieve an excellent polish on fragments of silica rich minerals or glass in this micrometer size range. The quickest method of verifying shocked minerals is electron backscatter diffraction. This technique requires an excellent polish on the mineral grains or the results are unsatisfactory. The second technique, that of verification by iridium anomalies, depends on a low background level of iridium in the layers above and below the projected impact layer. Because deep sea sediments

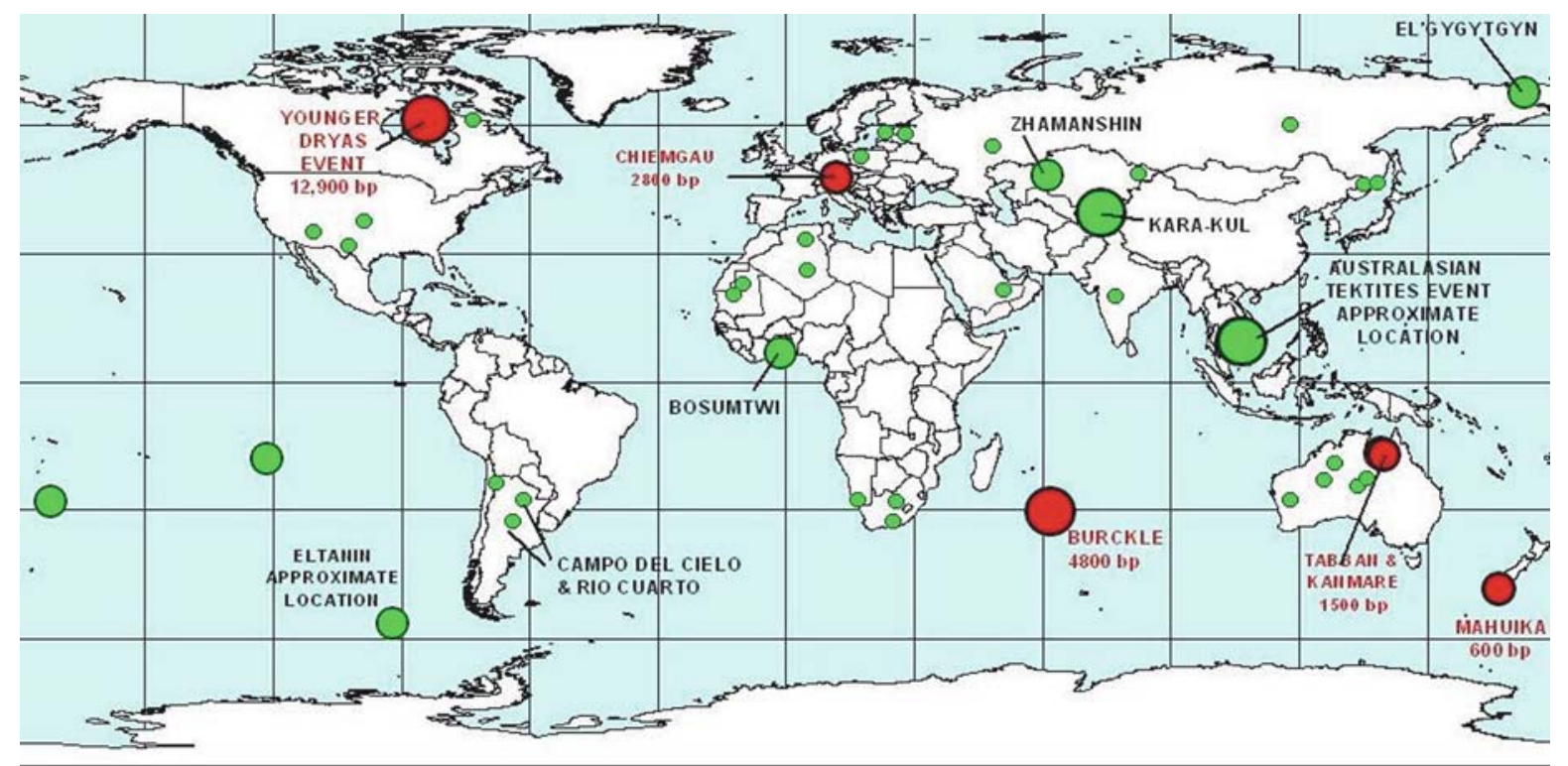

HYPOTHESIZED REGIONALLY CATASTROPHIC IMPACT

HYPOTHESIZED GLOBALLY CATASTROPHIC IMPACT

- VALIDATED LOCALLY CATASTROPHIC IMPACT [<10,000 MT]

VALIDATED REGIONALLY CATASTROPHIC IMPACT [10,000 to $1,000,000 \mathrm{MT}]$

VALIDATED GLOBALLY CATASTROPHIC IMPACT [>1,000,000 MT]

Fig. 9 Validated and selected hypothesized impacts by asteroids and comets during the past 5 million years 
accumulate slowly, the background level of iridium from cosmic dust is high. Thus, carbonate poor deepsea sediments are not suitable for verification of an impact layer by the detection of an iridium anomaly. The most common technique for verification of terrestrial impact craters is the confirmation of shocked quartz. Because deep sea basalts are not quartz normative, most contain no quartz at all. Thus, this third common technique is unsuitable for most oceanic impact cratering events.

\section{Gulf of Carpentaria Craters}

The Gulf of Carpentaria is a square marine basin on the north coast of Australia (Fig. 10). The Gulf of Carpentaria contains stable continental crust, with no evidence for tsunamigenic earthquakes $(M>7.0)$, recent landslides, or volcanic eruptions (Drummond et al. 1985). The Gulf of Carpentaria is connected to the open ocean via the Arafura Strait with a sill depth of $53 \mathrm{~m}$ (Smart

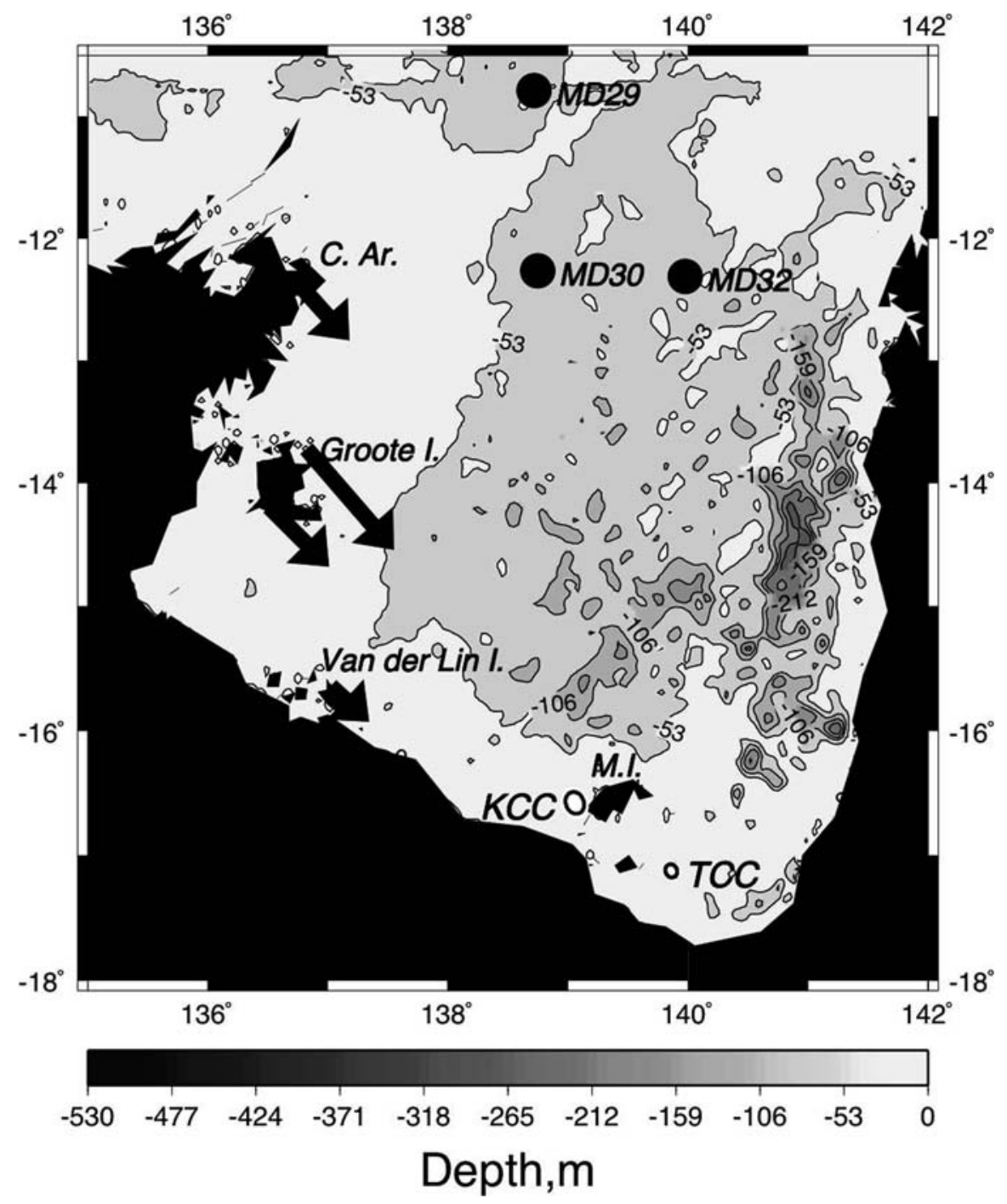

Fig. 10 Regional Map. Contour interval $53 \mathrm{~m}$. The sill depth of the Arafura Strait, the entrance to the Gulf of Carpentaria, is $53 \mathrm{~m}$. Greater water depths are darker. Continental areas are black. KCC: Kanmare Crater candidate. TCC: Tabban Crater candidate. M.I.: Mornington Island, C. Ar.: Cape Arnhem. Filled black circles are core locations. The three cores each contain a $\sim 1,500$ BP layer with magnetite impact spherules and impact glass. Arrows indicate the back azimuths of chevrons. These arrows are the inferred directions to the tsunami source of the chevrons (Kelletat and Scheffers, 2003) 
1977; Torgerson et al. 1983). As a result, low sea level in the early Holocene turned the Gulf into a brackish lake (Chivas et al. 2001; Jones and Torgerson 1988; Reeves et al. 2007). The brackish water produced extensive deposition of siderite $\left(\mathrm{FeCO}_{3}\right)$, a mineral absent from the open ocean except in micrometer sized fragments. Around 10,800 years ago, sea level rose and the Gulf of Carpentaria became an open marine basin (Reeves et al. 2007). Since that time, the Gulf has had a high sedimentation rate due to rapid deposition of marine microfossils composed of $\mathrm{CaCO}_{3}$.

We initially searched for impact craters in the Gulf of Carpentaria because Kelletat and Scheffers (2003) found chevron dunes with an orientation that implied a spatially restricted source area in the southeastern corner of the Gulf. They interpreted the chevron dunes as mega tsunami deposits. When we contoured bathymetry derived from satellite altimetry, we found two impact crater candidates that are 18 and $12 \mathrm{~km}$ in diameter (Fig. 11). Because of the unconsolidated nature of the sediment, we estimate that an impactor about $640 \mathrm{~m}$ in initial diameter could have fragmented to produce both craters.

\section{Discussion of Impact Ejecta}

Three cores from the Gulf of Carpentaria contain a thin layer with vitreous material, magnetite spherules, and occasional pure carbon and silicate spherules with an age of about 1500 B.P. (Martos et al. 2006; Abbott et al. 2007a, b). Although magnetite spherules can form as ablation products of meteorites, the magnetite spherules in the Gulf of Carpentaria are undoubtedly products of a terrestrial impact. The spherule in Fig. 12 has a quench texture and a perfect spherical form, implying that it is melting rather than eroding out of the sediment. The terrestrial origin of the sediment is clear in Fig. 12f. This figure shows that the sediment contains a replacement cast of a microfossil. The replacement cast is composed of iron oxide. The groundmass of the sediment is iron oxide with a $\mathrm{Cl}$ peak (Fig. 12c). The bright spots to the left of the spherule are barite (Fig. 12d). So far as we know, barite has never been found in a meteorite. Thus, the combination of fossil casts and barite points to a terrestrial source for the sediment. This implies that the magnetite spherules are the result of a terrestrial impact and are not ablation products of a meteorite.

\section{Examples of Chevron Dunes}

Figures 13 and 14 show examples of the chevron dunes first described in detail by Kelletat and Scheffers (2003). Figure 13 shows the chevron dunes on Groote Island, and Fig. 14 shows the chevron dunes on Van der Lin Island. The inferred maximum implied run-ups
Fig. 11 Topographic map. Bathymetry inferred from satellite altimetry (Sandwell and Smith, 2005). Contour interval $20 \mathrm{~m}$. Two crater candidates Kanmare and Tabban appear as elliptical topographic lows near Mornington Island. Black ellipses at the crater margins have average diameters of 18 and $12 \mathrm{~km}$ respectively

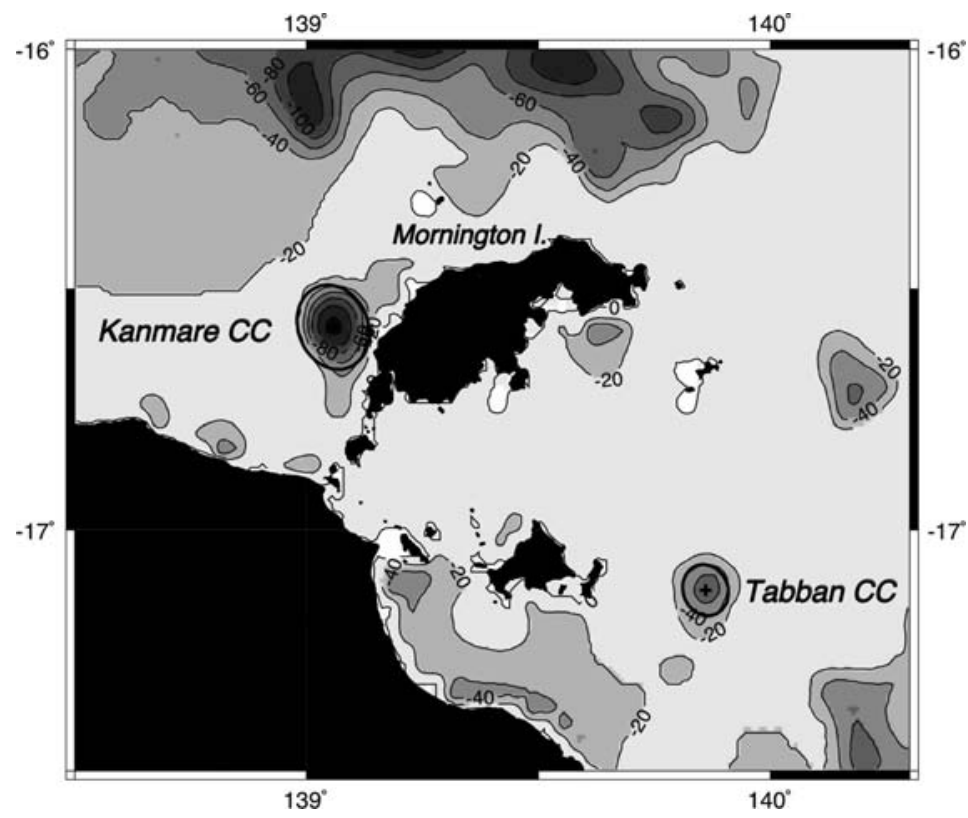




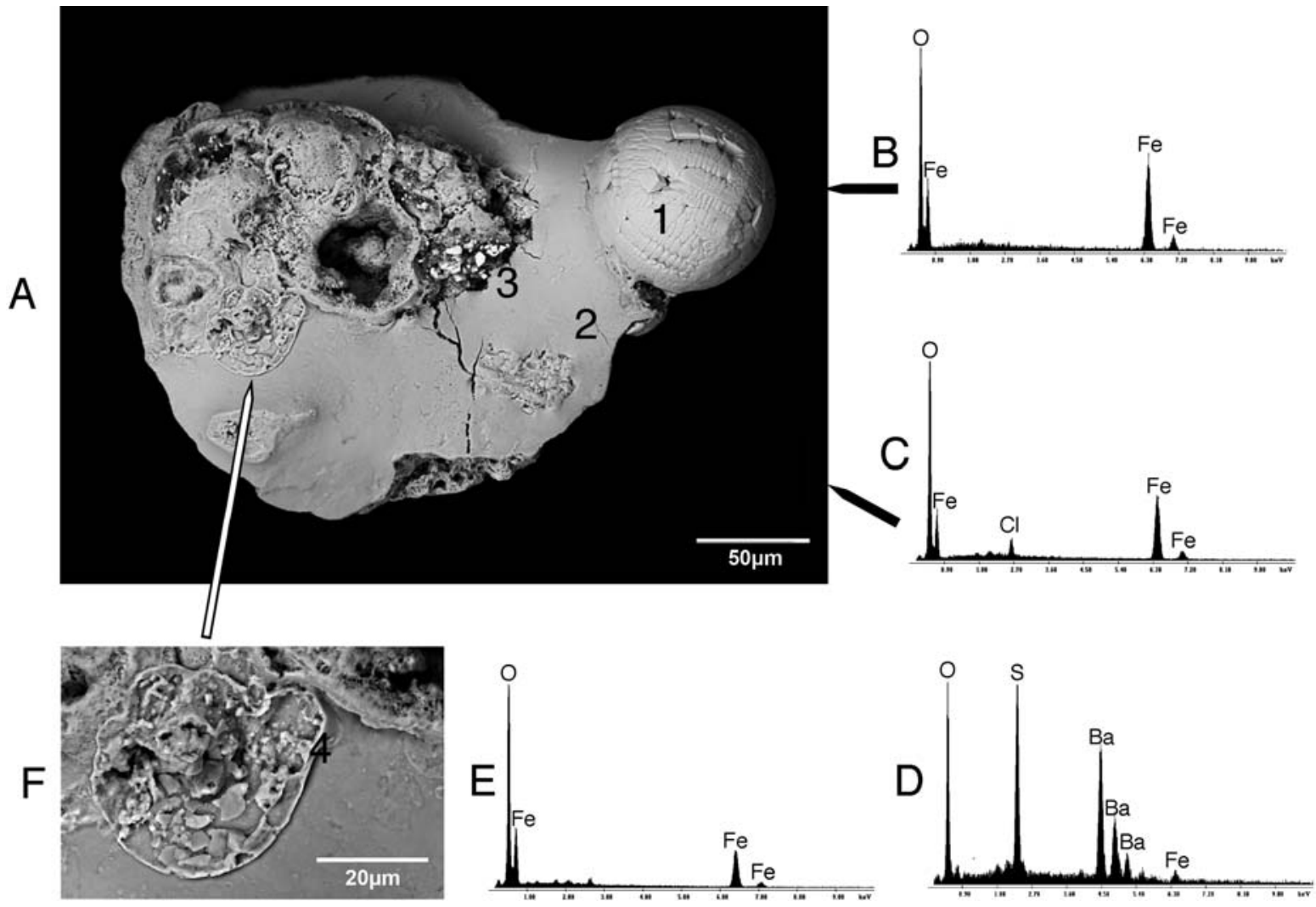

Fig. 12 Evidence for a terrestrial source rock for magnetite spherules. (a) Magnetite spherule with quench texture melting out of hematite rich marine sediment; (b) X-ray analysis of the composition of the quench textured spherule (1); (c) X-ray anal-

of the mega tsunami source are quite large, over $60 \mathrm{~m}$ above sea level on Groote Island and over $20 \mathrm{~m}$ on Van der Lin island.

\section{Discussion of the Hypothesized Gulf of Carpentaria Impact Event}

The hypothesis of a mega tsunami origin for the chevron dunes in the Gulf of Carpentaria is still controversial (Abbott et al. 2008a). The chevron dunes have an orientation that is close to but does not match the direction of the prevailing winds. The chevron dunes on Groote Island contain unusual lag deposits of shell. Because carbonate does not survive wind action, these lag deposits are a primary target for future investigation.

The circa 1,500 BP. spherules and glass we have found in three cores are undoubtedly impact ejecta from a terrestrial impact. The problem is to firmly link ysis of the composition of the groundmass (2); (d) X-ray analysis of the composition of brightest areas (3); (e) X-ray analysis of edge of fossil in F; (f) Enlarged image of fossil. (photo credit D.Breger) these ejecta to the two crater candidates in the southeastern part of the Gulf. In some cases, the magnetite spherules are melting out of rocks containing siderite, a mineral that is extremely rare in the open ocean and is relatively common in the Gulf of Carpentaria. This observation is consistent with the two crater candidates as source craters but is not definite proof. Geophysical imaging of the crater candidates and marine geological work on mapping changes in thickness of the impact ejecta layer are required to determine if the two crater candidates are the source of the impact ejecta layer in cores MD29, MD30 and MD 32.

\section{Burckle Crater and the Madagascar Chevrons}

\section{Burckle Crater}

We have identified an extremely large crater candidate (Burckle crater, $29 \mathrm{~km}$ in diameter) in the Indian 


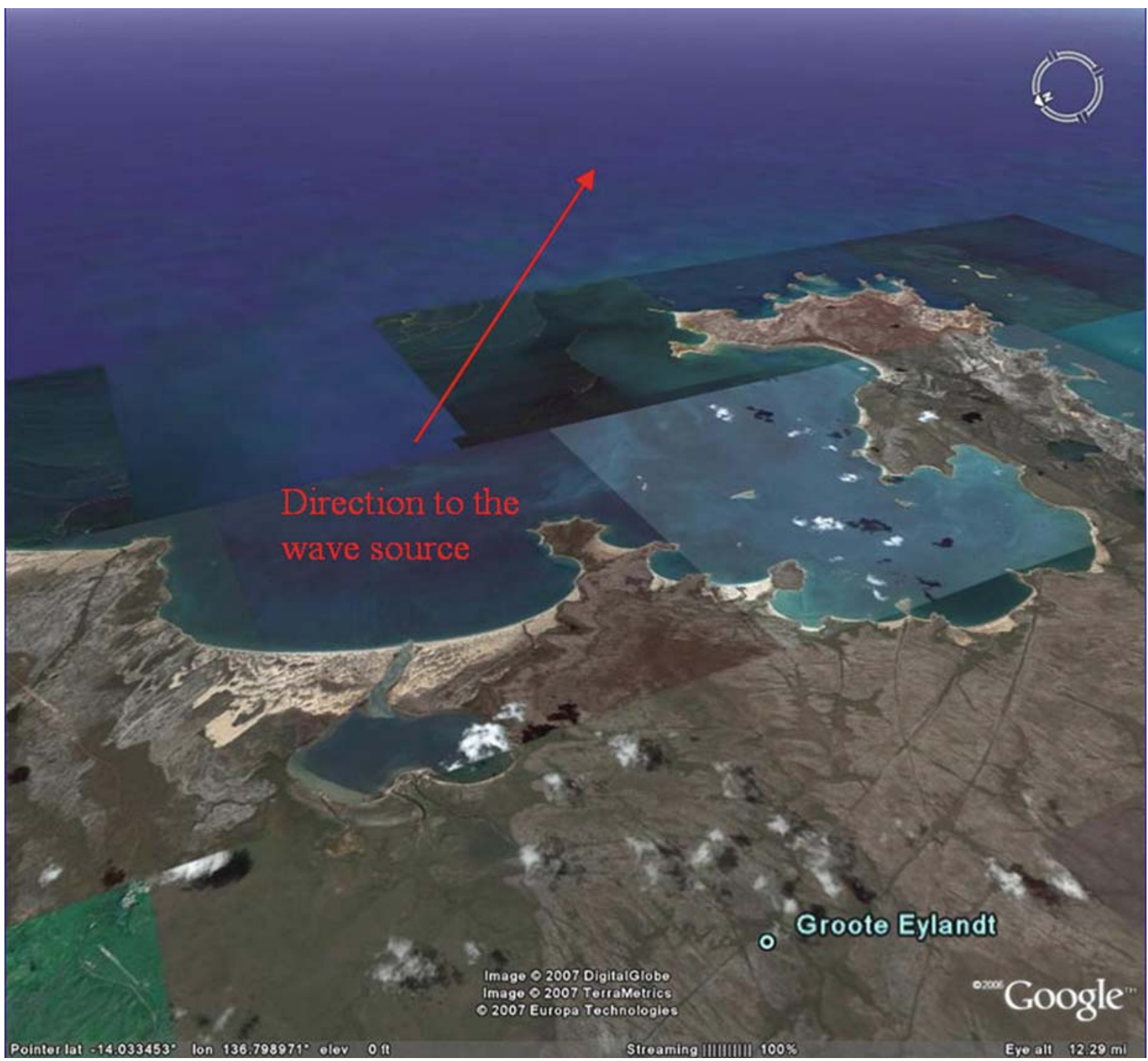

Fig. 13 Chevron dunes on Groote Eylandt in the Gulf of Carpentaria. The arrow depicts the direction of the wave source. Note the absence of large chevrons at the beach along the bay

Ocean at $31^{\circ} \mathrm{S}, 61^{\circ} \mathrm{E}$ (Fig. 15). We initially identified this crater in response to anthropological and archaeological work that pointed to the southern Indian Ocean as the source of a Holocene age impact (Masse 1998, 2007; Abbott et al. 2005). We found this crater using satellite altimetry, before there was any data on chevrons available on Google Earth. The latitude of this crater is identical to the latitude of Perth, Australia. Independently, Kelletat and Scheffers (2003) predicted that the tsunami source for chevrons in western Australia lay at the same latitude as Perth. Once we were on the right. This part of the bay is protected from waves coming from the source area but not from the prevailing winds

aware of their work, we realized that there should be even larger chevrons in Madagascar if our inferences about Burckle crater were correct. When Google Earth imagery became available, we found chevrons that were over $45 \mathrm{~km}$ long and extending to over 200 $\mathrm{m}$ above sea level in southern Madagascar.

Burckle crater is a round hole $29 \mathrm{~km}$ in diameter on the wall of a fracture zone south of the Southwest Indian Ridge (Fig. 16). Its morphology is subtle but we are certain that it is not a submarine volcanic edifice or a submarine fault block basin. Volcanic 


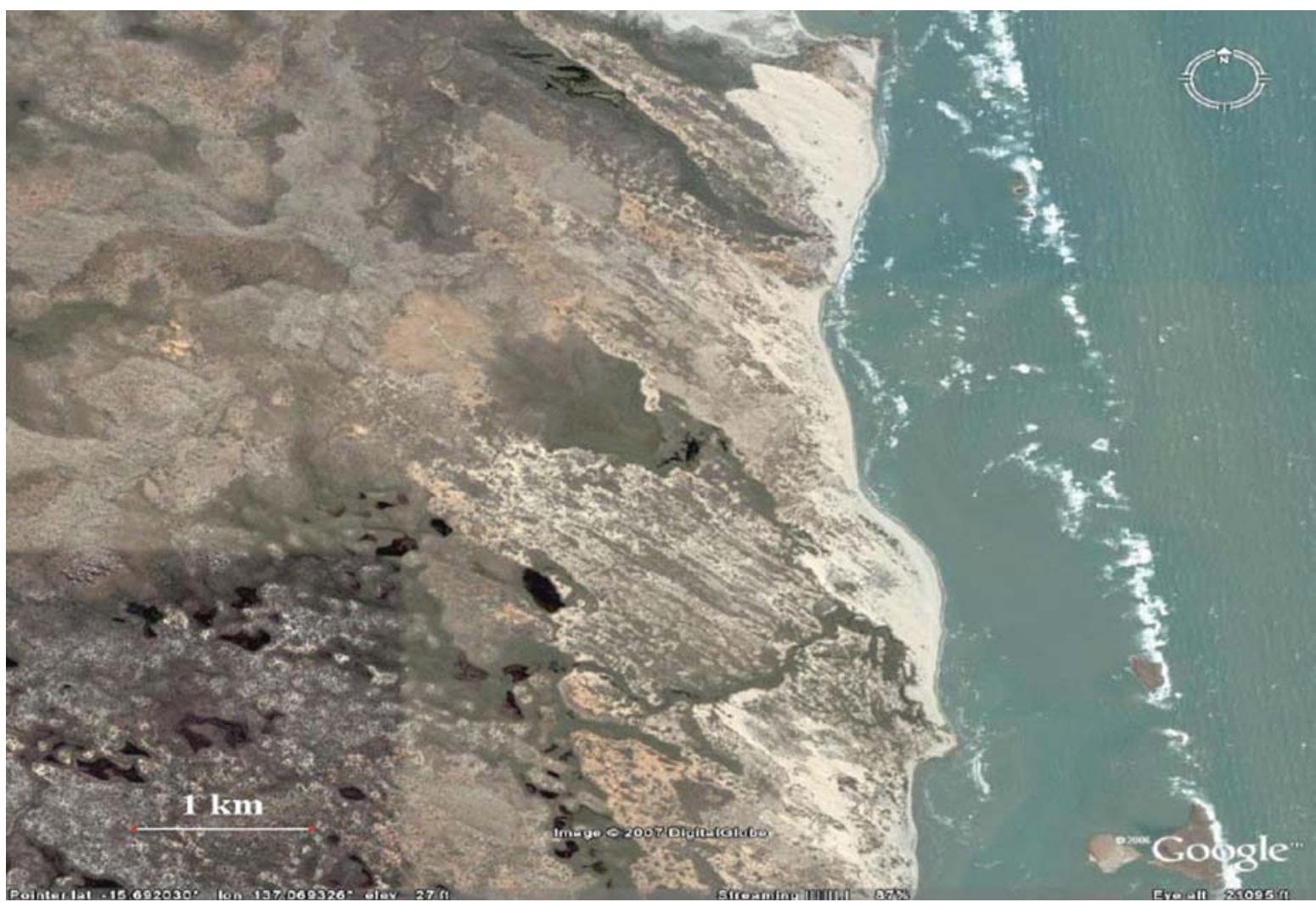

Fig. 14 Chevrons on Van der Lin Island, near south coast of the Gulf of Carpentaria

edifices have greater topographic relief. Volcanic edifices appear like flat-topped steep sided hills except when they are active. Submarine fault block basins are square rather than round. The low topographic relief of Burckle is expected for a submarine impact crater. Submarine impact craters form when an impactor with a diameter that is at least $1 / 10$ of the water depth strikes the sea floor (Davison and Collins 2007; Gault and Sonnett 1982). The impact crater forms in the rock, sediment, and water. After the initial explosion, the impact water cavity and associated sediment collapse inward, filling the interior of the crater (Tsikalas et al. 1999). Thus submarine impact craters have much more modest relief than impact craters of comparable diameter on land. The crater rim and walls are also eroded by the resurge of water into the crater, producing gullies (Sturkell 1998; Tornberg 1997). Three such prospective gullies are evident for Burckle crater (Fig. 16). Unfortunately, there is no actual geophysical data from the location of the proposed Buckle crater impact structure itself. All of our inferences about Burckle crater are based on satellite gravity determination of sea floor bathymetry (Sandwell and Smith 2005; Smith and Sandwell 1997).

Burckle crater has several characteristics that would likely produce some impact ejecta comparable to a giant $(>60 \mathrm{~km})$ crater in the ocean floor. Normal oceanic crust is 6-7 km thick (White et al. 1992). However, fracture zone crust may be nonexistent or at most 1-2 km thick (Mutter and Detrick 1984). Fracture zone walls often expose mantle rocks (Bonatti 1990; Michael and Bonatti 1985). Thus, Burckle's location on a fracture zone wall implies that its impact ejecta will contain mantle rocks such as serpentinized peridotites. The process of serpentinization enriches mantle rocks in calcium, and deposits veins of calcite. It may also contain some oceanic crustal rocks with a high abundance of plutonic rocks (gabbros) and fractionated rocks (oxide gabbros and plagiogranites) (Dick and Fisher 1984). Because impact craters 


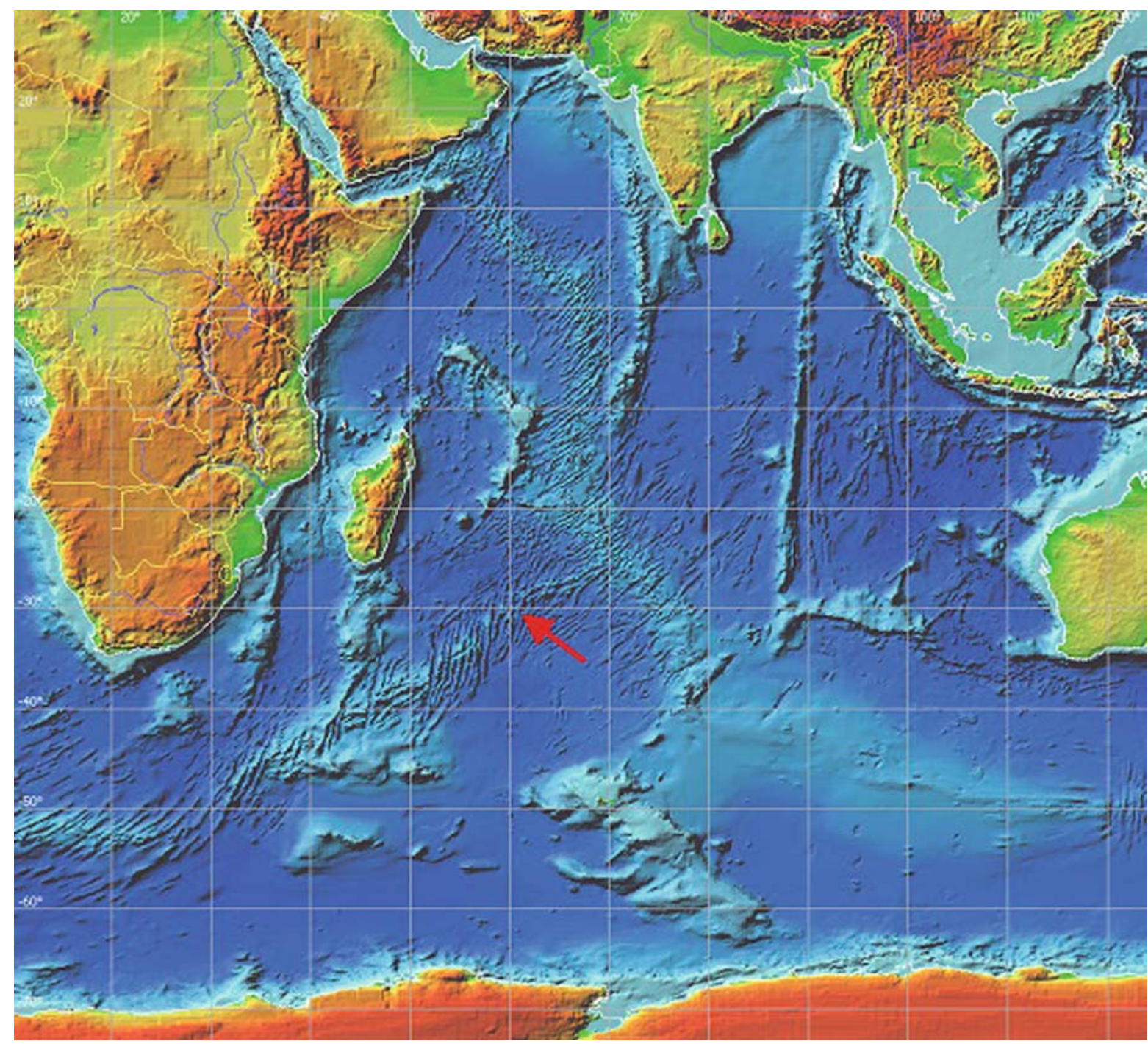

Fig. 15 Map of the approximate location of Burckle Crater candidate abyssal impact structure (arrow) along the southeast Indian Ridge. The map is adopted from the ETOPO5 topography coverage on the Integrated Tsunami DataBase for the Pacific and Indian Oceans CD-ROM (ITDB, 2005)

\section{Ejecta Mapped in Core Samples}

excavate rocks down to a depth that is about $1 / 10$ of their diameter (Melosh 1989), an impact onto normal oceanic crust might eject small amounts of gabbro; however, its dominant ejecta should be oceanic sediment and oceanic basalt. Impact ejecta composed of oceanic mantle would be absent unless the crater was at least $60 \mathrm{~km}$ in diameter. As craters over $60 \mathrm{~km}$ in diameter have a repeat time of tens of millions of years (Collins et al. 2005), Burckle is most likely the only impact in the last 2 million years that produced ejecta containing mantle rocks.
We have made preliminary estimates of the thickness of impact ejecta in five cores near Burckle crater candidate (Table 4, Fig. 17). Our estimated thicknesses of the ejecta layers are in general agreement with Burckle as the source crater. However, there is still great uncertainty about the overall thickness of the layers. This is due to the small sample sizes that we have worked with and the unusual nature of the ejecta. We have 
Fig. 16 (after Abbott et al., 2005) Topographic map. Contour interval: $360 \mathrm{~m}$. Large black circle: calculated edge of continuous ejecta blanket for a crater on land. Small black circle: rim of Burckle crater. Note the three major lows in the crater rim that are possible research gullies Dotted line: portions of seismic line showing no sediment cover. Solid black line: portions of seismic line showing sediment cover. The sediment is ponded in topographic lows creating locally smooth topography. Area to $\mathrm{N}$ and $\mathrm{W}$ of Burckle crater shows smooth topography and may represent the continuous ejecta blanket of Burckle crater

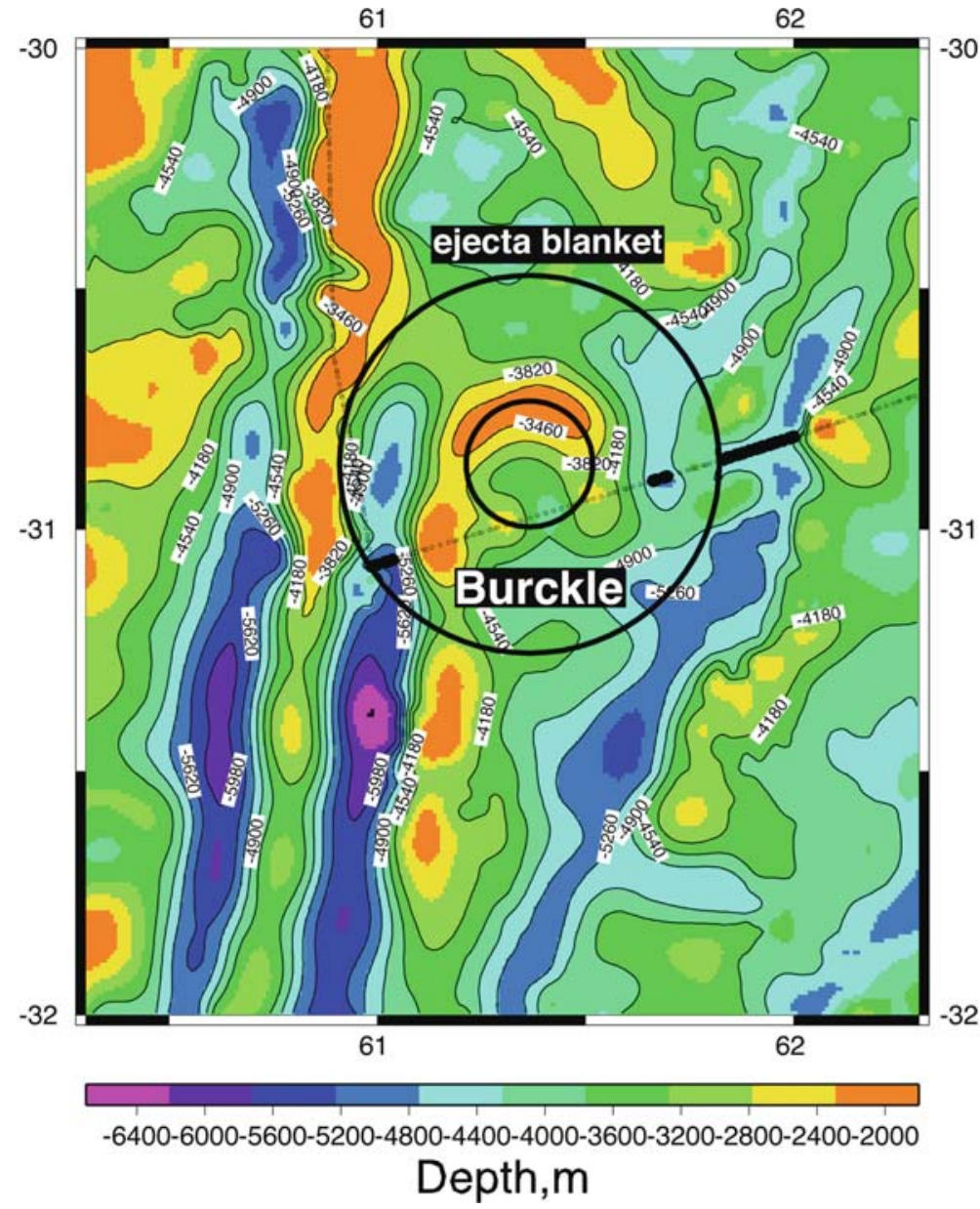

\begin{tabular}{llll}
\hline Core\# & $\begin{array}{l}\text { Distance to } \\
\text { Burckle, } \mathrm{km}\end{array}$ & $\begin{array}{l}\text { Observed } \\
\text { Thickness, } \mathrm{cm}\end{array}$ & $\begin{array}{l}\text { Modeled } \\
\text { Thickness, cm }\end{array}$ \\
\hline LSDA-123G & 77.7 & $>54$ & 279 \\
LSDA-122G & 118.7 & $67 \pm 5$ & 78.3 \\
LSDH-23G & 154.5 & $32 \pm 5$ & 32.8 \\
LSDA-124G & 228.8 & $>6$ & 10.9 \\
DODO-132P & 335.5 & $3 \pm 1$ & 3.5 \\
\hline
\end{tabular}

Table 4 Observed thicknesses of impact ejecta and modeled thickness (Collins et al. 2005) of ejecta from Burckle crater

\section{Nature of the Burckle Ejecta}

the minimum weight of sample we need to confidently identify the presence (or absence) of impact ejecta is between 10 and $20 \mathrm{~g}$. The cores we have been working with are old and heavily sampled. Thus, in many cases we could only obtain a 2-5 g sample. This size of sample is not large enough for us to confidently state that impact ejecta are absent from a given layer. Thus, our layer thicknesses are in many cases only minimum estimates.
The ejecta from cores near Burckle crater are unusual. We find mineral fragments, rock fragments, glass fragments, nearly pure carbon impact spherules, and calcite rhombohedrons (Fig. 18). The latter are the most common type of impact ejecta. Because the water depth at all of the coring sites is deep, it is impossible for these calcite rhombohedrons to represent in 


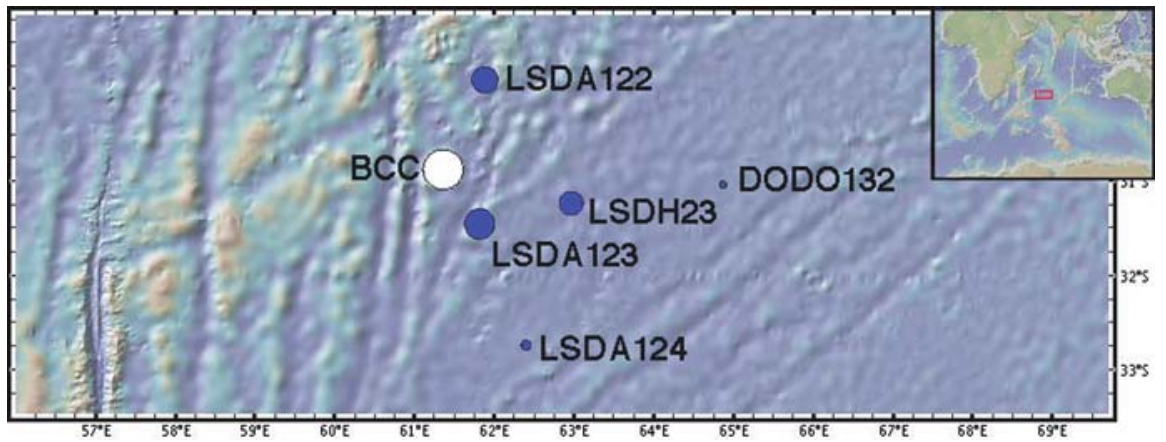

Fig. 17 Burckle Crater and Thickness of Ejecta Layer. Topographic map is from GeoMapApp. White circle: Location of Burckle Crater Candidate. Blue circles: Cores containing impact ejecta. Size of blue circle is directly proportional to the average

inferred thickness of the impact ejecta layer. Ejecta layers are thicker closer to the crater candidate and thinner further away from the crater candidate

Table 5 Water depths and ejecta types of material in core samples from Indian Ocean

\begin{tabular}{lll}
\hline Core\# & Depth, $\mathrm{m}$ & Ejecta Types \\
\hline LSDA-123G & 4,200 & Carbonate rhombs, native Fe, pyroxene, high C silicate glass, C spherule \\
LSDA-122G & 4,400 & Carbonate rhombs, olivine, pyroxene, C spherule \\
LSDH-23G & 4,910 & Carbonate rhombs, C spherule, glass \\
LSDA-124G & 4,780 & Carbonate rhombs, C spherule \\
DODO-132P & 4,805 & Carbonate rhombs, native Ni, native Fe \\
\hline
\end{tabular}

situ precipitates (Table 5). Seawater is not super saturated in calcite at any water depth this far south in the Indian Ocean. Carbonate fossils found with the calcite appear quite corroded, as would be expected for a location with bottom water that is heavily undersaturated in calcite. Thus, the preservation of these calcite rhombohedrons requires two circumstances: a mechanism to produce them locally and a mechanism to bury them quickly. Because Burckle crater candidate is situated on a fracture zone, it is possible that the calcite rhombohedrons represent cleavage fragments of the fracture zone crust and mantle. The crust and mantle of fracture zones are heavily altered by hydrothermal circulation. During this process, calcite veins are precipitated. These calcite veins would be broken apart during an impact event and could be the source of the calcite rhombohedrons that we find.

\section{The Madagascar Chevrons}

Mega tsunami chevrons are ubiquitous along the coast of southern Madagascar, more so than on any other coastline in the world (Fig. 19). They extend east in a nearly unbroken chain $375 \mathrm{~km}$ long from Itampolo Bay to a point midway between Mandrare
River and the city of Taolagnaro (Ft. Dauphin). In August-September 2006, D. Abbott, E. Bryant, and V. Gusiakov conducted two weeks of preliminary reconnaissance from Faux Cap to Ampalaza Bay. Participants made several traverses of the four largest chevron formations in this area-near Faux Cap, Cap St. Marie and along the coast of Fenambosy and Ampalaza Bays (Figs. 19, 20 and 21).

All investigated chevrons appear to consist of marine sand transported by water. In some cases, the chevrons overtopped the front edge of the Karimbola Plateau escarpment whose top is situated more than $125-150 \mathrm{~m}$ above the neighboring coastal plain (Fig. 21). Run-ups greater than $200 \mathrm{~m}$ have been documented throughout the Ambovombe area, although these features were erroneously considered windgenerated "paleo-dunes" by previous research (Clark et al. 1998). The Ambovombe chevrons have been largely masked due to intensive farming and wind activation of the original chevron dunes, but their general structure is clearly apparent in false color applications of satellite imagery (Clark et al. 1998: Fig. 10).

The two best delineated and preserved chevron dunes are those associated with Ampalaza and Fenambosy Bays (Figs. 20 and 21). The Ampalaza chevron 

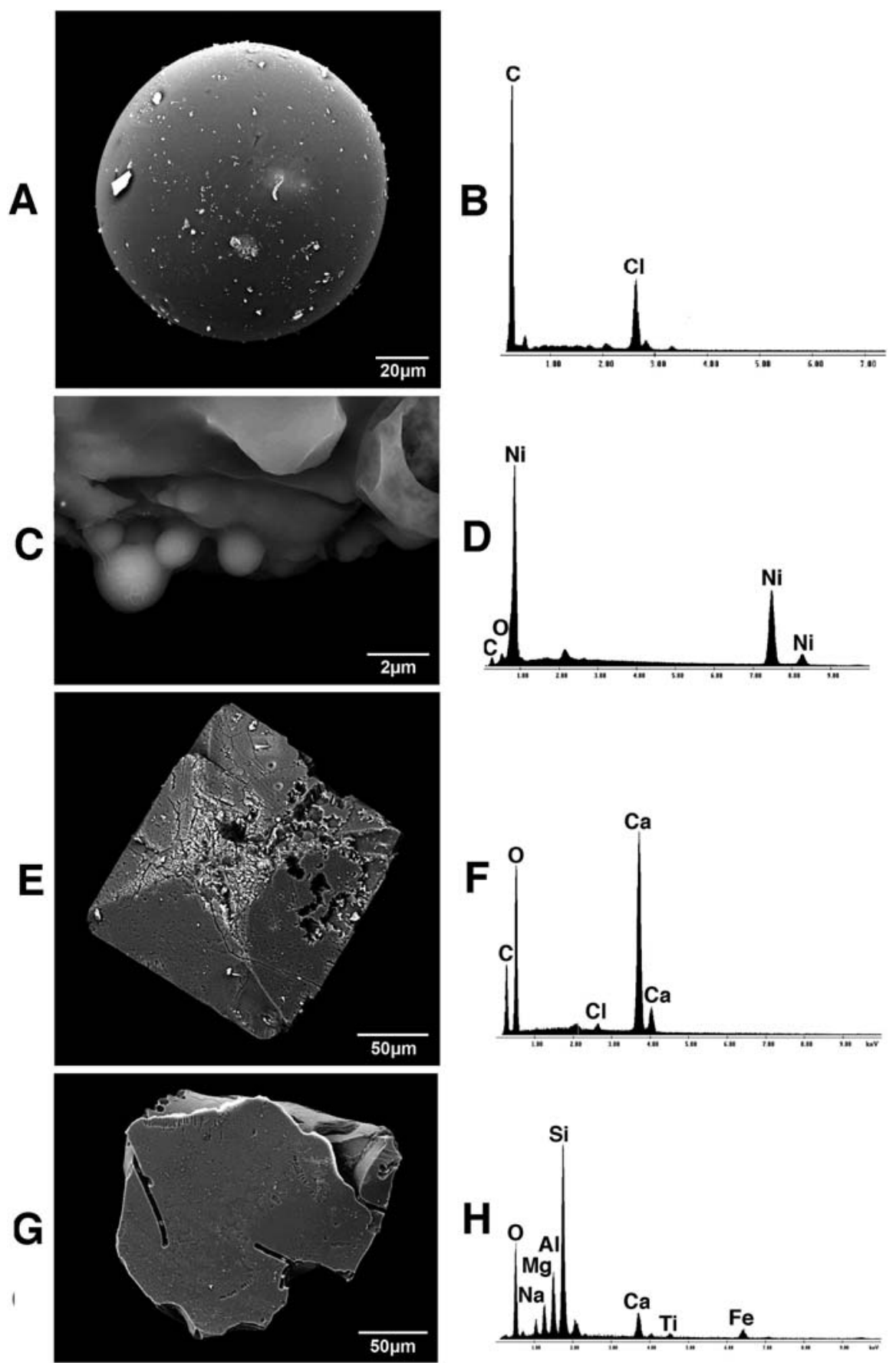

Fig. 18 Typical impact ejecta from cores near Burckle crater candidate. (a) Nearly pure c impact spherule from core LSDA122: 80-82 cm depth; (b) EDS (elemental X-ray) analysis of the c spherule in a; (c) Native Ni metal being melted (drops are $\mathrm{NiO}$ ) from core DODO132: 14-16 cm depth; (d) X-ray analysis of the native $\mathrm{Ni}$ in $\mathrm{c}$; (e) Calcite rhombohedron from core

LSDH23: 21-23 cm depth. The rhombohedron surface appears etched and contains tiny craters on upper tip; (f) EDS analysis of the calcite rhombohedron in e; (g) Glass with holes like worm burrows from core LSDA123: 22-24 cm depth. The hole shapes are not typical of volcanic glass; (h) EDS analysis of composition of the glass in $\mathrm{g}$. (photo credit - D.Breger) 


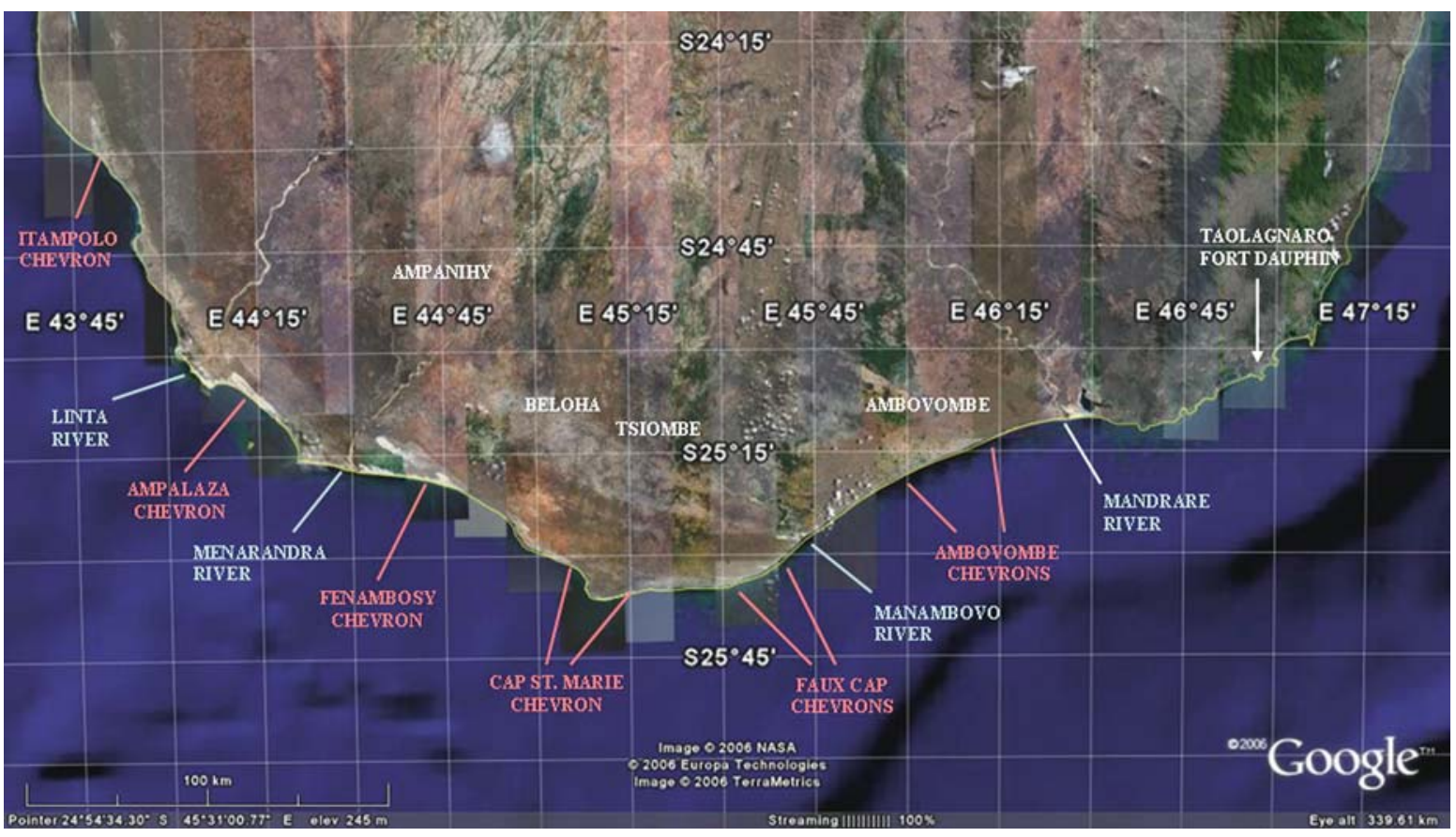

Fig. 19 Four systems of chevron dunes (Ampalaza, Cap St. Marie, Faux Cap, Fenambosy) on the southern coast of Madagascar studied during the 2006 expedition

is a remarkable $45 \mathrm{~km}$ in length from its base immediately to the east of Ampalaza Bay to its apex just short of confluence with the Linta River (Fig. 20). The tip of the apex (north of the village of Antanamilihitsa) reaches a height of approximately $80 \mathrm{~m}$ above present sea level.

There are a number of intriguing features associated with the chevron and its presumed formation by a mega tsunami wave(s). The first is that of the multiple sets of well-defined smaller internal chevrons which apparently resulted from the backwash of the largest mega tsunami wave. Also apparent is the fact that the Menarandra River delta appears to have lost much of its originally deposited sediment. We hypothesize that the mega tsunami wave scoured the delta, forming the lagoonal system west of the delta and ending up as part of the bulk of the Ampalaza chevron dune itself. That the chevron was created by surface water flow, is also seemingly evidenced by the orientation of river bottom sediments (probable silts) smeared across floodplain terraces northwest of the Linta River, and by the orientation of smaller chevrons near the bay. Together these features indicate both the complexity and magnitude of these mega tsunami deposits. [See Bourgeois and Weiss 2009 for a non-mega tsunami interpretation of the Madagascar chevrons]

As remarkable as is the Ampalaza chevron, in several respects the Fenambosy chevron (Fig. 21) is even more striking. Although the full length of the chevron is nearly $10 \mathrm{~km}$ less than that for Ampalaza, only approximately $35 \mathrm{~km}$ from base to apex, the height of run-up reaches a staggering $180 \mathrm{~m}$ above mean sea level at a point some $8 \mathrm{~km}$ inland from the coast. In reaching this elevation the mega tsunami wave fronted and eventually overtopped the Karimbola Plateau escarpment, the top of which averages about 140-150 $\mathrm{m}$ above mean sea level. Where the mega tsunami wave overtopped the escarpment rim, several sections show evidence of erosional channel scarring.

Critics of the mega tsunami genesis of the southern Madagascar chevrons point to what appears at first glance to be a match between the orientation of the chevrons and that of the prevailing winds. However, careful measurement of the orientation of each chevron instead reveals consistence with wave refraction patterns. Fig. 22 shows the systematic change in orientation of long axes of Madagascar chevrons consistent with the predicted azimuths of a tsunami wave com- 


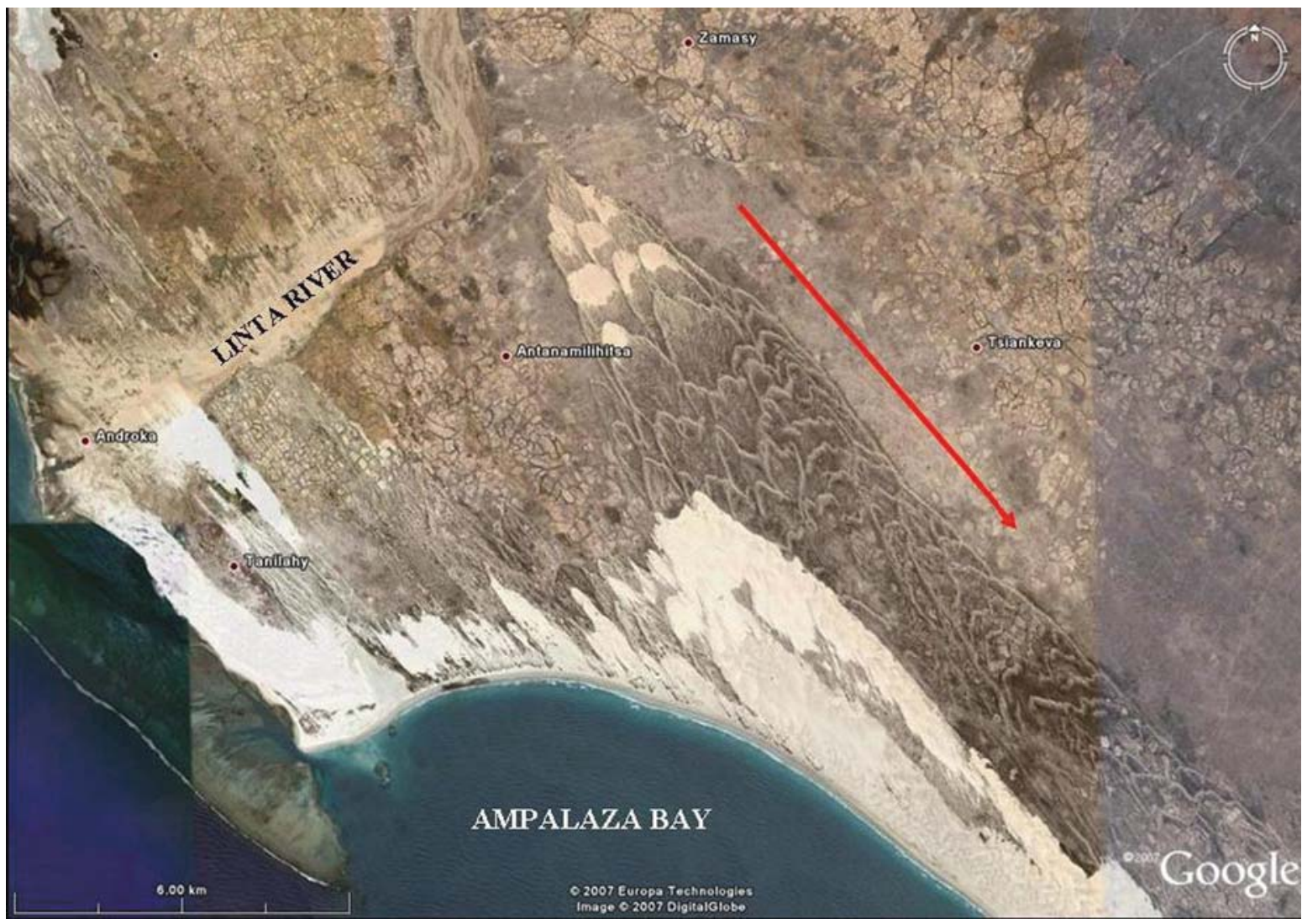

Fig. 20 Vertical Google Earth satellite image of the Ampalaza chevron, Madagascar. The red arrow points toward the tsunami source. The chevron apex (north of Antanamilihitsa) exhibits recent barchan dune activation

ing from a point source located in the vicinity of the Burckle crater candidate and refracted by sub-bottom topography near the southern coast of Madagascar.

In contrast to wind-blown dunes, which consist of a well sorted, unimodal size distribution, the Madagascar chevrons are unsorted with a broad range of particle sizes, from small boulders down to clay particles. They also include marine shells and microfossils (Fig. 23), with tentative species indentification being indicative of a source originally along the Madagascar outer shelf (Simon Haslett, personal communication 2008). We assume that a mega tsunami wave of the size indicated by the Madagascar chevrons should be able to entrain outer shelf sediments along with material closer to the coast. Dump deposits, containing rock fragments typical of mega tsunami processes, were found eastward from the Fenambosy chevron to Cap St. Marie. Many of the rock fragments were not locally derived. In addi- tion to wave run-ups of $80 \mathrm{~m}$ and $180 \mathrm{~m}$ found respectively at Ampalaza and Fenambosy, we documented maximum run-ups of ca. $200 \mathrm{~m}$ above present day sea level at Faux Cap and 190 m at Cap St Marie. Each chevron represents lateral transport of sediment onto the coast over many kilometers: $20 \mathrm{~km}$ at Faux Cap, $30 \mathrm{~km}$ at Fenambosy, and $45 \mathrm{~km}$ at Ampalaza.

Analysis of sediment samples collected from the southern Madagascar chevron reveals several features possibly indicative of cosmic impact. These include marine microfossils with surface splash particles of molten native metals. In addition, a number of the marine microfossils give the appearance of being "melted" as if from high temperatures (Fig. 23), although this could simply represent normal chemical weathering.

The age of the Madagascar chevrons is unknown. We estimate mid-Holocene (ca. 7,000-4,000 years old) 


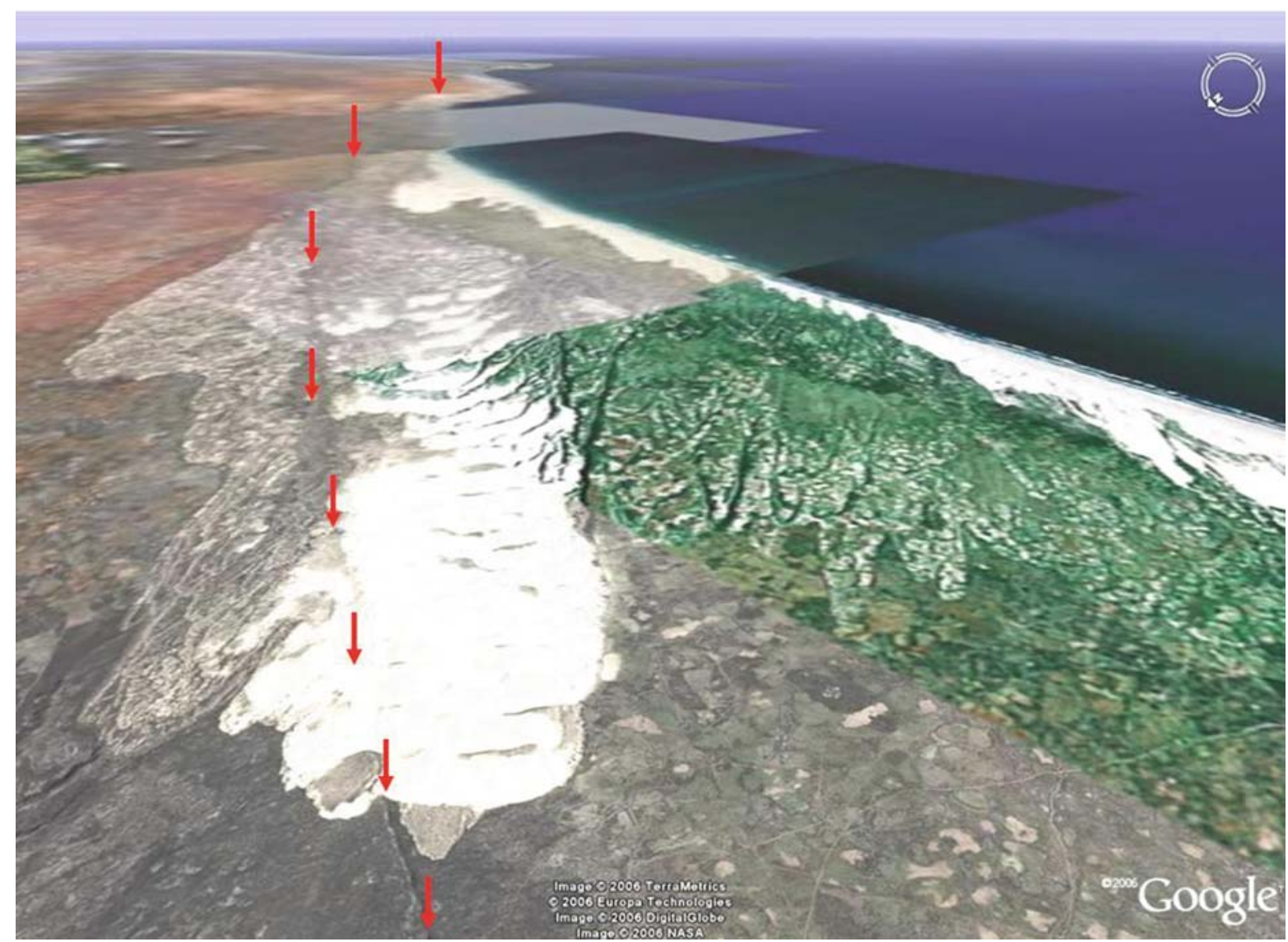

Fig. 21 Oblique view looking southeast at Fenambosy chevron. Arrows point to the top front edge of the 150-m-high Karimbola Plateau escarpment. White areas in the apex and the central portion of the chevron represent an extensive area of recently activated wind-blown dunes that are common also along coastal beaches. The green rectangle is an area of low resolution imagery based on general appearance and vegetation cover. They are no younger than AD 500 based on the radiocarbon dating of archaeological sites situated on top of the dunes, and they are almost certainly not older than the beginning of the Holocene Period. Chevrons are relatively fragile geomorphic features, and they would not have survived the dramatic changes that occurred during the Younger Dryas climatic event between 12,000 and 13,000 years ago and subsequent sea level rise. Portions of the chevrons have been disturbed by historic human activity during the estimated 2,500 years that people have lived on Madagascar (Blench 2006; Burney et al. 2004), and are being even more severely damaged by wind activation and the formation of incipient barchan dunes. Because the Madagascar chevron dunes are older than the arrival of humans on the island, unlike the Gulf of Carpentaria impact event, there seemingly is no oral history specific to the formation of these features.

\section{Rapid Climate Change}

There is no question that the larger recorded impacts on Earth, such as the Chicxulub Cretaceous-Tertiary (KT) boundary event, signal major rapid climatic shifts, and in the case of the KT impactor, associated significant species extinction. However, smaller impact events, in the range of $10^{4}-10^{6} \mathrm{Mt}$, are much less certain in terms of environmental and climatic effects, but they are of considerable concern due to the interconnected nature of modern society (MacCraken 2007). Some studies 


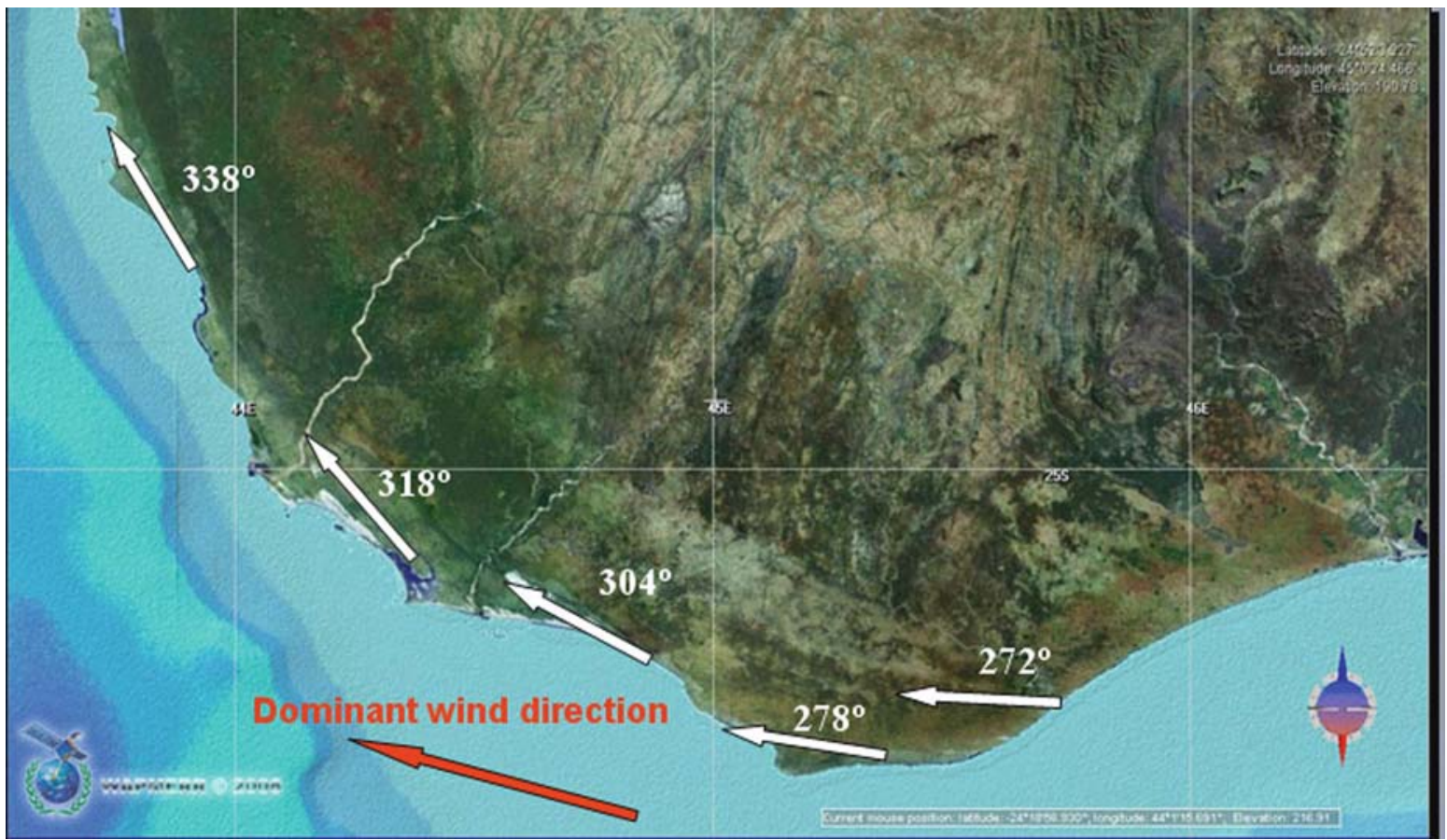

Fig. 22 Systematic change in orientation of Madagascar chevrons that is consistent with refraction pattern of incoming tsunami waves. Azimuth to the Burckle crater is $285^{\circ}$
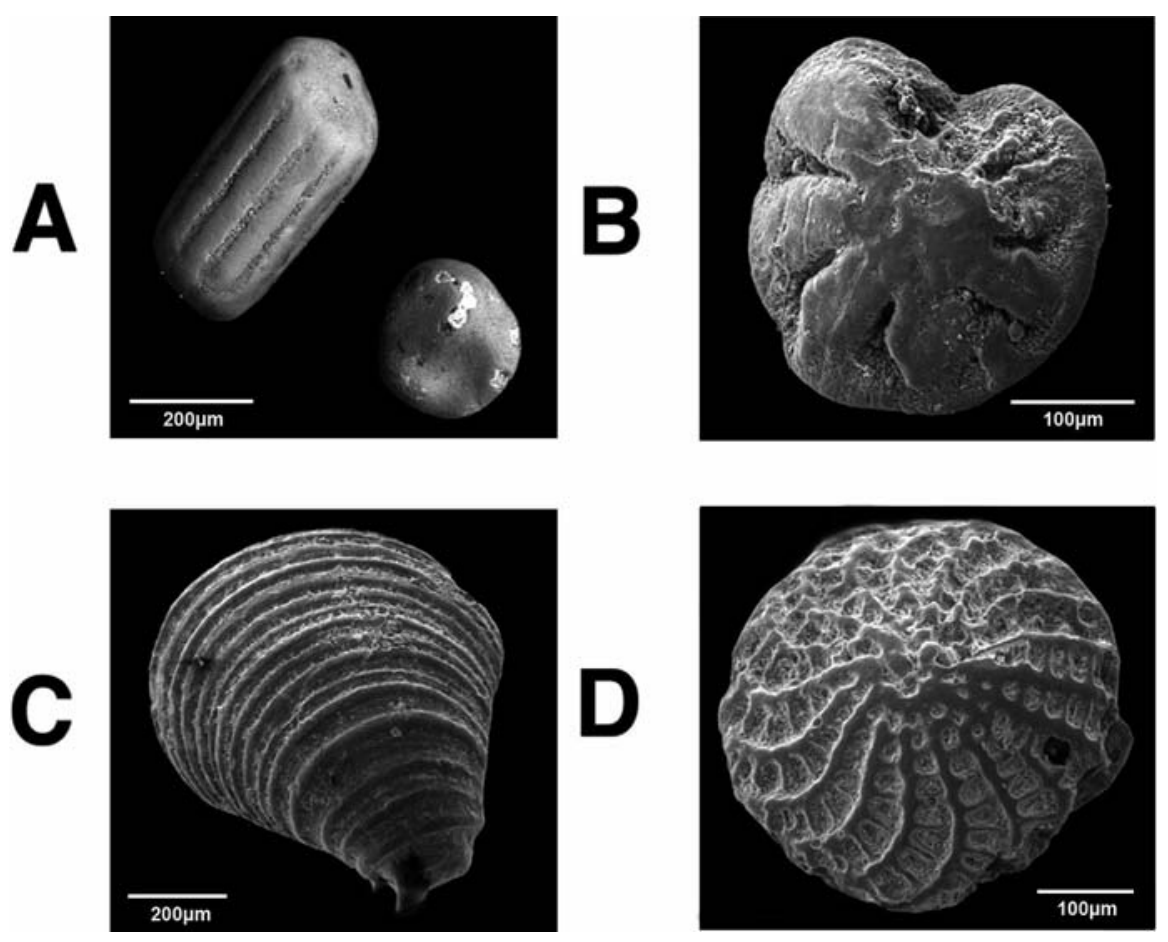

Fig. 23 Examples of well preserved fragment of coral (a) and "melted" (b) and "unmelted" (d) benthonic foraminifera, found in sediment samples collected from the Madagascar chevrons.
The other specimen (c) has not yet been identified (photo credit - D. Breger) 
have even indicated that impactors between 150 and $1,000 \mathrm{~m}$ in diameter are capable of causing significant ozone depletion (Birks et al. 2007). Most studies suggest that significant environmental perturbations and short-term climatic effects would not be expected for impactors under about $1 \mathrm{~km}$ in diameter and yielding energies less than around $10^{5} \mathrm{Mt}$ (e.g. Chapman 2007), with long-term climatic effects being the consequence of "globally catastrophic" impactors between 2 and $3 \mathrm{~km}$ in diameter and an energy release between $10^{6}$ and $10^{7}$ Mt (Toon et al. 1997; Chapman 2007).

Of considerable interest for our research, then, is the possibility that the hypothesized Gulf of Carpentaria twinned impact and the Burckle crater-Madagascar chevron impact are temporally associated with environmental perturbations and the rapid onset of climate change.

The Burckle crater-Madagascar chevron impact is proposed to date to around 4,800 BP (Masse 2007), which would then make it roughly coincident with the climatic boundary shift between the middle to late Holocene, variously dated at between 5,000 and 4,800 BP. This climatic boundary shift is both poorly dated and its genesis uncertain; however, it generally represents a permanent change from warmer-dryer conditions to a cooler-wetter climatic regime at least for mush of the northern hemisphere, and also seems to signal Hong et al. 2005 a shift in the periodicity and intensity of the El Niño-Southern Oscillation pattern (e.g., Cane 2005; Hong et al. 2007). These effects are suggested as being consonant with the atmospheric injection of considerable water vapor and aerosols from an abyssal impact of around $10^{6} \mathrm{Mt}$ indicated by the apparent size of Burckle crater candidate impact structure, and from mega tsunami effects noted in southern Madagascar and on the western coast of Australia. Documentary and archaeological evidence (Masse 2007) suggests that the impact resulted in an extended period of virtually worldwide atmospheric rainout and associated cyclonic storms that stopped after 7-10 days once water vapor in the atmosphere approached pre-impact levels. Storm surges during the cyclonic activity would have devastated many oceanic coasts that normally are not subject to cyclone activity.

Our present dating for the Gulf of Carpentaria chevrons and the presence of likely impact microejecta in oceanic sediment cores places the hypothesized impact in the sixth century AD. This dating then suggests a potential relationship with the 536-
545 "years without a summer" climatic perturbation (Abbott et al. 2008b). The Kanmare and Tabban hypothesized impact structures are indicative of an impact between approximately $10^{4}-10^{5} \mathrm{Mt}$, perhaps suitable for the sun-obscuration and cooling temperatures historically documented for this period (Rigby et al. 2004). Unlike the Burckle crater event, the Gulf of Carpentaria impacts would have lofted less water and more sediment particles into the atmosphere, thus creating aerosol dispersion probably similar to that associated with massive ultra-Plinian volcanic eruptions. The environmental and climatic effects lasted several years, resulting in a period of crop failure and starvation, but were not permanent as was the apparent case with the hypothesized larger Burckle crater impact.

The Burckle crater and Gulf of Carpentaria impacts take on added significance in light of ongoing studies associated with the proposed Laurentide ice sheet impact at $12,900 \mathrm{BP}$ that allegedly triggered the dramatic beginning of the Younger Dryas climatic cooling event (Firestone et al. 2007). The Younger Dryas perturbation lasted more than 1300 years, resulting in massive northern hemisphere vegetation change, megafaunal extirpations and extinctions, and apparent major effects on human populations.

Thus these three climatic events, that of 12,900 , 4,800 , and $1,500 \mathrm{BP}$, have potential major ramifications if caused by cosmic impact, rather than by more pedestrian terrestrial causes.

\section{Conclusions}

1. Available historical data show that the largest possible seismogenic and volcanic tsunamis can hardly exceed $45-50 \mathrm{~m}$ in their maximum run-up at the nearest coast with $15-20 \mathrm{~m}$ run-up in the farfield. Landslide-generated tsunamis can be highly destructive locally, but never flood any extended part of the coast. Meanwhile, the world ocean's coastline contains prominent erosional and depositional features of catastrophic water currents and waves of much higher magnitude.

2. The measured run-up heights (100-200 m) and inland penetration (tens of kilometers) of these features over the extended part of the coast are far beyond the range produced by the largest histor- 
ically known tectonic tsunamis (seismic and volcanic). Such great run-ups can be produced only by large-volume submarine landslides or oceanic impacts. In the latter case, such impacts may also be responsible for major environmental downturns in the Holocene that are contemporaneous with those implied by tree-ring records, lake-bottom sediment analyses, and ice-core data.

3. The Gulf of Carpentaria crater candidates have several lines of evidence in favor of a bolide impact origin. The first is their overall morphology derived from satellite altimetry. The second is the occurrence of clear terrestrial impact ejecta in the form of impact spherules and vitreous material. The impact spherules are mostly iron oxide but a few silicate spherules and pure carbon spherules are also present. We have found iron oxide spherules with quench textures melting out of rocks that contain fossils, barite, and siderite. This allows us to rule out an origin for the iron spherules as ablation spherules derived from meteorites. The impact ejecta occur as a well defined, $\sim 1 \mathrm{~cm}$ thick layer in three piston cores and have an age of about 1,500 BP. The third line of evidence is that the local chevrons all have azimuths that point back towards the locations of the crater candidates. The chevron orientations do not precisely match the direction of the prevailing wind. Finally, some chevrons contain $10 \mathrm{~cm}$ thick lag deposits of shell, and are locally absent where the coast is shielded by flat, off shore islands. Although these three lines of evidence are consistent with an impact into the Gulf of Carpentaria around 1,500 BP, they are not definitive proof. Geophysical surveys of the craters and marine geological mapping of the thickness variations and composition of the proximal ejecta blanket are needed to confirm the proposed impact origin of the Carpentaria crater candidates.

4. Our work on the Burckle crater candidate in the central Indian Ocean shows evidence of an impact ejecta layer that is thicker towards the crater candidate. The ejecta layer contains calcite rhombs, pyroxene, plagioclase, and olivine fragments, pure carbon spherules, and impact glass. Our findings are still preliminary due to the small sizes of available samples. These cores are heavily sampled and have been degraded during decades of storage. The bathymetry around Burckle crater is mostly derived from single line bathymetric tracks and satellite altimetry. It is located just at the edge of the ridge crest area that has been surveyed using modern multibeam bathymetric mapping. The hypothesis of an impact into this area could be tested by taking and sampling new kasten cores and by multibeam bathymetric mapping and a gravity/magnetic survey of the crater candidate. A modern marine geological and marine geophysical survey is needed to assess the nature and origin of the Burckle crater candidate.

5. The Madagascar chevrons, the largest on the planet, are situated on land that is closest to the Burckle crater candidate. Their systematic change in orientation is consistent with the refraction around the southern coast of Madagascar of a large tsunami whose source area approximates the Burckle crater candidate. The marine microfossils and coarse debris found in the Madagascar chevrons are derived from sites that are as much as $170 \mathrm{~m}$ above sea level and over $7 \mathrm{~km}$ in a direct line from the coast. The Ampalaza chevron is being more reworked by wind then surrounding soils and it is not suitable for farming. We therefore conclude that human beings did not bring in the marine microfossils and coarse debris we have found. In addition, the fossils are often concentrated in lag deposits and occur over $40 \mathrm{~km}$ along the strike of the chevrons. The fossils appear well preserved in these lag deposits. We find it highly unlikely that such well-preserved carbonate fossils could have been transported over a distance up to $40 \mathrm{~km}$ overland to these sites by the wind. Thus, our overall conclusion is that the Madagascar chevrons were most likely produced by a mega tsunami generated in a source area close to, or at the site of, the Burckle crater candidate.

6. In terms of rapid climate change, if even one of the three environmental/climatic events of ca. $12,900,4,800$, and $1,500 \mathrm{BP}$ was caused by a cosmic impact, the concept of a cosmic impact during the terminal Pleistocene and late Holocene would have significant ramifications for how we currently understand and model past climate change. If all three were demonstrated to be caused by cosmic impact, there would be a crucial need to rethink everything from our current use of paleoclimate proxies to model global warming, to that of our understanding of human biological and cultural evolution. The risks and potential devastat- 
ing consequences of oceanic impacts by comets and asteroids would need serious reconsideration with regard to future human coastal population and infrastructure.

With the data currently available, we cannot prove conclusively that the craters identified in the Gulf of Carpentaria or at the site of the Burckle candidate crater are impacts. But our study demonstrates that there is enough geomorphic and mineralogical evidence to suggest that such a hypothesis cannot be dismissed outright. Present disaster management is based on the type and frequency recurrence of the disasters that have been observed on the time scale of hundreds of years (e.g. Gad-el-Hak 2008). Disasters that occur, instead, on the scale of thousands of years, such as volcanic mega eruptions or significant cosmic impacts, are almost completely ignored despite being potentially massive in scope and effect. Moreover, a considerable part of the disaster community does not believe that catastrophic impacts by comets and asteroids have actually occurred during the course of human history. It is true that in terms of the evaluation of present day human loss statistics this type of global disaster has zero input. But cosmic impacts have so great a potential for large scale damage and fatalities, that their inclusion in the overall risk evaluation of natural hazards cannot be ignored.

Before 26 December 2004, a similar false premise existed in terms of the risk from tsunami. In the twentieth century, tsunamis were responsible for less than $0.5 \%$ of human fatalities resulting from natural disasters. The large death toll of over 230,000 victims that resulted from the 2004 Indian Ocean tsunami was neither predictable in terms of the total number of deaths or the location of the disaster. However in terms of twenty-first century risk from natural disasters, this statistic will remain a benchmark for a long time ... until the next great earthquake occurs in a large metropolitan area. Based on our field studies and laboratory analyses, the hypothesis of recent Holocene oceanic impacts is valid and requires serious consideration in the assessment of risks due to natural hazards.

Acknowledgements The authors wish to thank Mrs. T. Kalashnikova for assistance in preparing the figures and tables, and undertaking the final formatting of the manuscript. This work was partly supported by the RFBR grants 08-07-00105, 0905-00294, and 07-05-13583, and NSF Grant OCE06-49024. Authors also appreciate the financial support provided by the WAPMERR (Geneva, Switzerland) for the 2006 Madagascar field trip, along with the field support provided by University of Antananarivo graduate students H. Razafindrakoto and A. Raveloson. D. Breger conducted the scanning electron microscopy and assisted with the X-ray analyses. We thank the centralized research facilities of Drexel University for the use of their SEM/EDS system.

\section{References}

Abbott DH, Biscaye P, Cole-Dai J, Breger D (2008b) Magnetite and silicate spherules from the GISP2 core at the 536 A.D. horizon. EOS Transactions, American Geophysical Union, Fall Meeting Supplement, Abstract PP41B-1454:89

Abbott DH, Bryant EA, Gusiakov V, Masse WB, Breger D (2008a) Impacts, mega-tsunami, and other extraordinary claims. Comment, GSA Today, 18(6):12

Abbott DH, Masse WB, Burckle L, Breger D, Gerard-Little P (2005) Burckle abyssal impact crater: did this impact produce a global deluge? Proceedings of Atlantis 2005 Conference: Milos, Greece

Abbott DH, Tester EW, Meyers CA (2007a) Impact ejecta and megatsunami deposits from a historical impact into the Gulf of Carpentaria. Geological Society of America, Abstracts with Programs, vol 39, p 312

Abbott DH, Tester EW, Meyers CA, Breger D, Chivas AM (2007b) Sediment transport, mixing, and erosion by an impact generated tsunami: Gulf of Carpentaria, Australia. EOS Transactions, American Geophysical Union, Abstract OS31B-07:88

Baillie MG (2007) Tree-rings indicate global environmental downturns could have been caused by comet debris. In: Bobrowsky, PT, Rickman H (eds) Comet/Asteroid Impacts and Human Society: An Interdisciplinary Approach. Springer, Berlin, pp 105-122

Baker VR (ed) (1981) Catastrophic flooding: the origin of the channeled scabland. Dowden Hutchinson \& Ross, Stroudsburg, PA

Barrientos G, Masse WB (2009) Mid-Holocene cosmic impacts in central and northeastern Argentina: exploring probable effects on human population dynamics. Submitted to American Antiquity

Birks JW, Crutzen PJ, Roble RG (2007) Frequent ozone depletion resulting from impacts of asteroids and comets. In: Bobrowsky, PT, Rickman H (eds) Comet/Asteroid Impacts and Human Society: An Interdisciplinary Approach. Springer, Berlin, pp 225-245

Blench R (2006) New palaezoogeographical evidence for the settlement of Madagascar. Conference on The Maritime Heritage and Cultures of the Western Indian Ocean in Comparative Perspective, Zanzibar, Stone Town

Bobrowsky P, Rickman H (eds) (2007) Comet/asteroid impacts and human society: an interdisciplinary approach. Springer, Berlin

Bonatti E (1990) Subcontinental mantle exposed in the Atlantic Ocean on St. Peter-Paul islets. Nature, 345:800-802

Bourgeois J, Weiss R (2009) "Chevrons" are not megatsunami deposite-A sedimentologic assessment. Geology, 37:403-406.

Bryant E (2001) Tsunami: the underrated hazard, Cambridge University Press, Cambridge. Praxis, Chichester 
Bryant E (2008) Tsunami: the underrated hazard, 2nd edition. Praxis, Chichester

Bryant E, Walsh G, Abbott D (2007) Cosmogenic mega-tsunami in the Australia region: are they supported by Aboriginal and Maori Legends? In: Piccardi, L, Masse, WB (eds) Myth and Geology. Geological Society of London Special Publication 273, London, pp 203-214

Bryant EA, Young RW (1996) Bedrock-sculpturing by tsunami, South Coast New South Wales, Australia. Journal of Geology, 104:565-582

Burney DA, Burney LP, Godfrey LR, Jungers WL, Goodman SM, Wright HT, Jull AJ (2004) A chronology for late prehistoric Madagascar. Journal of Human Evolution, 47:25-63

Cane MA (2005) The evolution of El Nino, past and future. Earth and Planetary Science Letters, 230:227-240

Chapman CR (2007) The asteroid impact hazard and interdisciplinary issues. In: Bobrowsky, PT, Rickman H (eds) Comet/Asteroid Impacts and Human Society: An Interdisciplinary Approach. Springer, Berlin, pp 145-162

Chivas A, Garcia A, van der Kaars, S, Couapel MJJ, Holt S, Reeves JM, Wheeler DJ, Switzer AD, Murray Wallace CV et al. (2001) Sea-level and environmental changes since the last interglacial in the Gulf of Carpentaria, Australia: an overview. Quaternary International, 83-85:19-46

Clark CD, Garrod SM, Parker-Pearson M (1998) Landscape archaeology and remote sensing in southern Madagascar. International Journal of Remote Sensing, 19:1461-1477

Collins GS, Melosh HJ, Marcus R (2005) Earth impact effects program: a web-based computer program for calculating the regional environmental consequences of a meteoroid impact on earth. Meteoritics and Planetary Science, 40:817-840

Davison T, Collins G (2007) Investigating the effect of water depth on marine impact crater morphology. Workshop on Impact Cratering II, 8041

Dick HJB, Fisher RL (1984) Mineralogic studies of the residues of mantle melting: abyssal and Alpine-type peridotites. In: Komprobst, J (ed) Kimberlites II: The Mantle and CrustMantle Relationships. Amsterdam, Elsevier, pp 292-308

Drummond BJ, Denham D, Michael-Leiba M (1985) Rheology of the lithosphere and Australian earthquakes. Geology and Geophysics, Bureau of Mineral Resources, p 60

Firestone RB, West A, Kennett JP, Becker L, Bunch TE, Revay ZS, Schulz PH, Belgya T, Kennett DJ, Erlandson JM, Dickensen OJ, Goodyear AC, Harris RS, Howard GA, Kloosterman JB, Lechler P, Mayewski PA, Montgomery J, Poreda R, Darrah T, Hee SSQ, Smith AR, Stich A, Topping W, Wittke JH, Wolbach WS (2007) Evidence for an extraterrestrial impact 12,900 years ago that contributed to the megafaunal extinctions and the Younger Dryas cooling. Proceedings of the National Academy of Sciences, 104:16016-16021

Gad-el-Hak M (ed) (2008) Large-scale disasters: predictions, control, and mitigation. Cambridge University Press, Cambridge

Gault DE, Sonnett CP (1982) Laboratory simulation of pelagic asteroidal impact: atmospheric injection, benthic topography, and the surface wave radiation field. In: Silver, LT, and Schultz, PH (eds) Geological Implications of Impacts of Large Comets and Asteroids on the Earth. Geological Society of America Special Paper 190, pp 69-92

Gisler GR, Weaver RP, Mader CL, Gittings MR (2003) Two and three dimensional simulations of asteroid ocean impacts. Science of Tsunami Hazards, 21:119
Gusiakov VK (2003) NGDC/HTDB meeting on the historical tsunami database proposal. Tsunami Newsletter, 35(4):9-10

Gusiakov VK (2009) Tsunami history. In: Robinson A, Bernard E (eds). The Sea, Tsunamis. Harvard University Press, Cambridge, vol 15, pp 23-53

Hearty PJ, Neumann AC, Kaufman DS (1998) Chevron ridges and runup deposits in the Bahamas from storms late in Oxygen-Isotope substage 5e. Quaternary Research, 50: 309-322

Hills JG, Mader CL (1997) Tsunami produced by the impacts of small asteroids. Annals of the New York Academy of Sciences, 822:381-394

Hong YT, Hong B, Lin QH, Shibata Y, Hirota M, Zhu YX, Leng XT, Wang Y, Yi L (2005) Inverse phase oscillations between the East Asian and Indian Ocean summer monsoons during the last 12,000 years and paleo-El Nino. Earth and Planetary Science Letters, 231:337-346

ITDB (2005) Integrated tsunami database for the Pacific and Indian Oceans, version 6.1 of 31 July 2005. Intergovernmental Oceanographic Commission - Tsunami Laboratory of the Institute of Computation Mathematics and Mathematical Geophysics, SD RAS, Novosibirsk, CD-ROM.

Iwasaki SI (1997) The wave forms and directivity of a tsunami generated by an earthquake and a landslide. Science of Tsunami Hazards, 15:23-40

Jones MR, Torgerson T (1988) Late quaternary evolution of Lake Carpentaria on the Australia-New Guinea continental shelf. Australian Journal of Earth Sciences, 35:313-324

Kawana T, Nakata T (1994) Timing of Late Holocene tsunamis originated around the Southern Ryukyu Islands, Japan, deduced from coralline tsunami deposits. Japanese Journal of Geography, 103:352-376

Kelletat D (2008) Comments to Dawson, A.G. and Stewart, I. (2007) Tsunami deposits in the geological record. Sedimentary Geology, 211(3-4):87-91

Kelletat D, Scheffers A (2003) Chevron-shaped accumulations along the coastlines of Australia as potential tsunami evidences. Science of Tsunami Hazards, 21:174-188

Kindler P, Strasser A (2000) Paleoclimatic significance of cooccuring wind and water induced sedimentary structures in the last interglacial coastal deposits from Bermuda and the Bahamas. Sedimentary Geology, 131:1-7

Kor PSG, Shaw J, Sharpe DR (1991) Erosion of bedrock by subglacial meltwater, Georgian Bay, Ontario: a regional view. Canadian Journal of Earth Science, 28:623-642

Lander JF (1996) Tsunamis affecting Alaska, 1737-1996. United States National Geophysical Data Center. Key Geophys. Research Document 31

MacCraken MC (2007) The climatic effects of asteroid and comet impacts: Consequences for an increasingly interconnected society. In: Bobrowsky P, Rickman, $\mathrm{H}$ (eds) Comet/Asteroid Impacts and Human Society: An Interdisciplinary Approach: Berlin. Springer, Berlin, pp 277-289

Martos SN, Abbott DH, Elkinton HD, Chivas AR, Breger D (2006) Impact spherules from the craters Kanmare and Tabban in the Gulf of Carpentaria. Geological Society of America, Abstracts with Programs, 38:299-300

Masse WB (1998) Earth, air, fire, and water: the archaeology of Bronze Age cosmic catastrophes. In: Peiser BJ, Palmer T, Bailey ME (eds) Natural catastrophes during Bronze Age civilizations: archaeological, geological, astronomical, 
and cultural perspectives. BAR International Series 728, Archaeopress, Oxford, pp 53-92

Masse WB (2007) The Archaeology and Anthropology of Quaternary Period Cosmic Impact. In: Bobrowsky P, Rickman H (eds) Comet/Asteroid Impacts and Human Society: An Interdisciplinary Approach. Springer, Berlin, pp 25-70

Masse WB, Masse MJ (2007) Myth and catastrophic reality: using myth to identify cosmic impacts and massive Plinian eruptions in Holocene South America. In: Piccardi, L, Masse, WB (eds) Myth and Geology. Geological Society of London Special Publication 273, London, pp 177-202

Masse WB, Weaver RP, Abbott DH, Gusiakov VK, Bryant EA (2007) Missing in action? Evaluating the putative absence of impacts by large asteroids and comets during the quaternary period. Proceedings of the Advanced Maui Optical and Space Surveillance Technologies Conference, Wailea, Hawaii, pp 701-710

Maxwell TA, Haynes CV (1989) Large-scale, low amplitude bedforms (chevrons) in the Selima Sand Sheet. Science, 243:1179-1182

Melosh HJ (1989) Impact cratering: a geologic process. Oxford University Press, New York

Michael PJ, Bonatti E (1985) Peridotite composition from the North Atlantic: regional and tectonic variations and implications for partial melting. Earth and Planetary Science Letters, 73:91-104

Morrison D, Harris AW, Sommer G, Chapman CR, Carusi A (2002) Dealing with the impact hazard. In: Bottke W, Cellino A.,Paolicchi P, Binzel RP (eds) Asteroids III, University of Arizona Press, Tucson, pp 739-754

Mutter JC, Detrick RS (1984) Multichannel seismic evidence for anomalously thin crust at Blake Spur Fracture Zone. Geology, 12:534-537

Pinegina TK, Bourgeois J (2001) Historical and paleo-tsunami deposits on Kamchatka, Russia: long-term chronologies and long-distance correlations. Natural Hazards and Earth System Sciences, 1:177-185

Reeves JM, Chivas AR, Garcia A, Deckker PD (2007) Paleoenvironmental change in the Gulf of Carpentaria (Australia) since the last interglacial based on Ostracoda. Paleogeography, Paleoclimatology, Paleoecology, 246:163-187

Rigby E, Symonds M, Ward-Thompson D (2004) A comet impact in AD 536? Astronomy and Geophysics, 45: $1.23-1.26$.
Sandwell DT, Smith WHF (2005) Retracking ERS-1 altimeter waveforms for optimal gravity field recovery. Geophysical Journal International, 163:79-89

Scheffers A (2004) Tsunami imprints on the Leeward Netherlands Antilles (Aruba, Curaçao, Bonaire) and their relation to other coastal problems. Quaternary International, 120: 163-172

Scheffers AM, Kelletat DH, Scheffers SR, Abbott DH, Bryant EA (2008) Chevrons-enigmatic sedimentary coastal features. Zeitschrift für Geomorphologie, 52:375-402

Schultz PH, Lianza RE (1992) Recent grazing impacts on the Earth recorded in the Rio Cuarto crater field, Argentina. Nature, 355:232-237

Smart J (1977) Late quaternary sea-level changes, Gulf of Carpentaria, Australia. Geology, 5:755-759

Smith WHF, Sandwell DT (1997) Global seafloor topography from satellite altimetry and ship depth soundings. Science, 277:1956-1962

Sturkell E (1998) The marine Lockne impact structure, Jamtland, Sweden: a review. Geological Rundschau, $87: 253-267$

Toon OB, Zahnle K, Morrison D, Turco RP, Covey C (1997) Environmental perturbations caused by the impacts of asteroids and comets. Review of Geophysics, 35:41-78

Torgerson T, Hutchinson MF, Searle DE, Nix HA (1983) General bathymetry of the Gulf of Carpentaria and the quaternary physiography of Lake Carpentaria. Palaeogeography, Palaeoclimatology, Palaeoecology, 41:207-225

Tornberg R (1997) Impact-related resurge sediments as exemplified by the Lockne, Tvaeren and Kaerdla structures. Geological Society of America, Abstracts with Programs, 29(6):80

Tsikalas F, Gudlaugsson ST, Faleide JI, Eldholm O (1999) Mjolnir Structure, Barents Sea; a marine impact crater laboratory. In: Dressler, BO, Sharpton, LV, (eds) Large meteorite impacts and planetary evolution. Geological Society of America, Special Paper 339, pp 193-204

White RS, McKenzie D, O’Nions RK (1992) Oceanic crustal thickness from seismic measurements and rare earth element inversions. Journal of Geophysical Research, 97: 19683-19715

Young R, Bryant E, Price DM (1996) Catastrophic wave (tsunami?) transport of boulders in southern New South Wales, Australia. Zeitschrift für Geomorphologie, 40: 191-207 